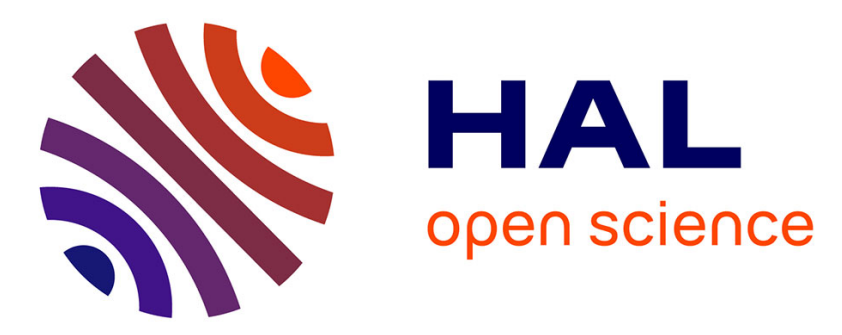

\title{
A posteriori error estimator and indicator in Generalized Finite Differences. Application to improve the approximated solution of elliptic pdes.
}

\author{
Juan J Benito, Francisco Ureña, Luis Gavete, Beatriz Alonso
}

\section{To cite this version:}

Juan J Benito, Francisco Ureña, Luis Gavete, Beatriz Alonso. A posteriori error estimator and indicator in Generalized Finite Differences. Application to improve the approximated solution of elliptic pdes.. International Journal of Computer Mathematics, 2008, 85 (03-04), pp.359-370. 10.1080/00207160601167052 . hal-00545346

\author{
HAL Id: hal-00545346 \\ https://hal.science/hal-00545346
}

Submitted on 10 Dec 2010

HAL is a multi-disciplinary open access archive for the deposit and dissemination of scientific research documents, whether they are published or not. The documents may come from teaching and research institutions in France or abroad, or from public or private research centers.
L'archive ouverte pluridisciplinaire HAL, est destinée au dépôt et à la diffusion de documents scientifiques de niveau recherche, publiés ou non, émanant des établissements d'enseignement et de recherche français ou étrangers, des laboratoires publics ou privés. 


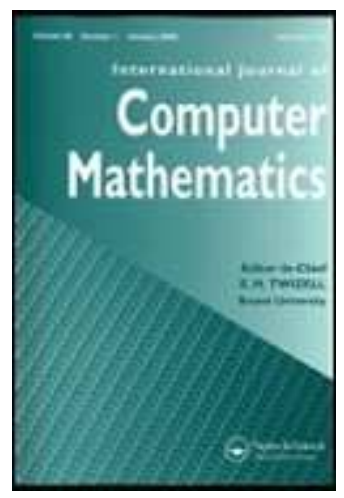

\section{A posteriori error estimator and indicator in Generalized Finite Differences. Application to improve the approximated solution of elliptic pdes.}

\begin{tabular}{|c|c|}
\hline Journal: & International Journal of Computer Mathematics \\
\hline Manuscript ID: & GCOM-2006-0146.R1 \\
\hline Manuscript Type: & Original Article \\
\hline $\begin{array}{r}\text { Date Submitted by the } \\
\text { Author: }\end{array}$ & 05-Dec-2006 \\
\hline Complete List of Authors: & $\begin{array}{l}\text { Benito, Juan; Universidad Nacional Educación a Distancia, } \\
\text { Ingeniería de Construcción y Fabricación } \\
\text { Ureña, Francisco; Universidad de Castilla La Mancha, Matemática } \\
\text { Aplicada } \\
\text { Gavete, Luis; Universidad Politécnica Madrid, Matemática Aplicada a } \\
\text { los Recursos Naturales } \\
\text { Alonso, Beatriz; Universidad Politécnica Madrid }\end{array}$ \\
\hline Keywords: & $\begin{array}{l}\text { generalized finite differences, meshless methods, posteriori error, } \\
\text { adaptive method, Partial differential equations }\end{array}$ \\
\hline \multicolumn{2}{|c|}{$\begin{array}{l}\text { Note: The following files were submitted by the author for peer review, but cannot be converted } \\
\text { to PDF. You must view these files (e.g. movies) online. }\end{array}$} \\
\hline jcm4.tex & \\
\hline
\end{tabular}

\section{scholarONE \\ Manuscript Central}


International Journal of Computer Mathematics

Vol. 00, No. 00, Month 200x, 1-9

\title{
A posteriori error estimator and indicator in Generalized Finite Differences. Application to improve the approximated solution of elliptic pdes (SI-CMMSE-2006)
}

\author{
J.J. BENITO ${ }^{1 *}$, F. URENA ${ }^{2}$, L. GAVETE ${ }^{3}$ and B. ALONSO ${ }^{3}$ \\ ${ }^{1}$ Departamento de Construcción y fabricación, Universidad Nacional de Educación a Distancia, Spain \\ ${ }^{2}$ Departamento de Matemática Aplicada, Universidad de Castilla-La Mancha, Spain \\ ${ }^{3}$ Departamento de Matemática Aplicada a los Recursos Naturales, Universidad politécnica de Madrid, Spain \\ (Received 00 Month 200x; revised 00 Month 200x; in final form 00 Month 200x)
}

\begin{abstract}
In this paper we compare two different procedures of approximation of the posteriori error for the GFD method, both procedures are residual based errors. The performance of the two different approximations of the error is illustrated by analysing different second order partial differential equations in 2-D problems with known analytical solutions, using irregular cloud of points. Also, in this paper an adaptive method for improving solutions using a posteriori error is shown.
\end{abstract}

Keywords: generalized finite differences, meshless methods, a posteriori error approximation, adaptive method

AMS Subject Classifications: F.1.1; F.4.2 (Authors: Please substitute appropriate classification codes)

\section{Introduction}

The classical finite difference method (FDM) emerged as an approximate discrete method of analysis of boundary-value problems given in the form of differential equations and appropriate boundary conditions. The idea of using an eight node star and weight functions to obtain finite difference formulae for irregular meshes, was first put forward by Liska and Orkisz [6,7], using moving least squares (MLS) interpolation, and the most advanced version of the Generalized Finite Element Method (GFDM) was given by Orkisz $[2,8,9]$, including: mesh generation, local approximation, generation of finite difference (FD) formulae and FD equations resulting from local (collocation) or global (Galerkin,variational,) formulations. GFDM is included in the so-called Meshless Methods (MM) [1,2].

In this paper we compare the posteriori error indicator for the GFD method developed by Benito et al. $[4,5,10]$ with a posteriori error estimator based on Orkis'z works $[1,8,9]$. Also, in this paper, an h-adaptive method is shown, for improving the approximate solution of the second order partial differential equation. The paper is organized as follows. Section 3 describes the posteriori error indicator. Section 4 describes the posteriori error estimator. Section 5 describes an adaptive method in generalized finite differences. Section 6 illustrates the posteriori error approximations at work and the efficiency of the adaptive method for the solution of elliptic equations using irregular clouds of points. Finally, in Section 7 some conclusions are given.

*Corresponding author. Email: jbenito@ind.uned.es

International Journal of Computer Mathematics ISSN 0020-7160 print/ISSN 1029-0265 online (c) 200x Taylor \& Francis http://www.tandf.co.uk/journals

DOI: $10.1080 / 0020716$ YYxxxxxxxx 


\section{The generalized finite difference method}

Let us to consider a problem governed by

$$
\alpha_{1} \frac{\partial U}{\partial x}+\alpha_{2} \frac{\partial U}{\partial y}+\alpha_{3} \frac{\partial^{2} U}{\partial x^{2}}+\alpha_{4} \frac{\partial^{2} U}{\partial y^{2}}+\alpha_{5} \frac{\partial^{2} U}{\partial x \partial y}=f(x, y) \quad \text { in } \quad \Omega
$$

with boundary condition

$$
\beta \frac{\partial U}{\partial n}+\gamma U=g(x, y) \quad \text { in } \quad \Gamma
$$

where $\Omega \subset R^{2}$ with boundary $\Gamma ; \alpha_{i}, i=1, \cdots, 5, \beta$ and $\gamma$ are constant coefficients; and $f, g$ are two known smoothed functions.

First of all, it is necesary to generate a grid of points (it can be irregular) in the domain that we call nodes. Then, every node in the domain is the central node of a set of nodes around it. We call this a star. If $U_{0}$ and $U_{i}$ are approximations of the function at the central node and at the rest of nodes of the star, with $i=1 . . N$ (in this paper the number of star nodes is $N=8$, two nodes for each quadrants $[4,5]$ ). Then, according to the Taylor series expansion it is known that

$$
U_{i}=U_{0}+h_{i} \frac{\partial U_{0}}{\partial x}+k_{i} \frac{\partial U_{0}}{\partial y}+\frac{1}{2}\left(h_{i}^{2} \frac{\partial^{2} U_{0}}{\partial x^{2}}+k_{i}^{2} \frac{\partial^{2} U_{0}}{\partial y^{2}}+2 h_{i} k_{i} \frac{\partial^{2} U}{\partial x \partial y}\right)+\cdots
$$

where $\left(x_{0}, y_{0}\right)$ are the coordinates of the central node, $\left(x_{i}, y_{i}\right)$ the coordinates of the $i^{t h}$ node in the star and $h_{i}=x_{i}-x_{0} ; k_{i}=y_{i}-y_{0}$. If the unwritten terms in the equation (3) are ignored, an approximation of second order for the $U_{i}$ function is obtained, which is indicated as $u_{i}$. It is then possible to define the function $B_{5}(u)$ (subindex refers to the number of unknowns in the functional) as in $[6,7]$ and $[4,5]$

$$
B_{5}(u)=\sum_{i=1}^{N}\left[\left(u_{0}-u_{i}+h_{i} \frac{\partial u_{0}}{\partial x}+k_{i} \frac{\partial u_{0}}{\partial y}+\frac{h_{i}^{2}}{2} \frac{\partial^{2} u_{0}}{\partial x^{2}}+\frac{k_{i}^{2}}{2} \frac{\partial^{2} u_{0}}{\partial y^{2}}+h_{i} k_{i} \frac{\partial^{2} u}{\partial x \partial} y\right) w\left(h_{i}, k_{i}\right)\right]
$$

where $B_{5}(u)$ is norm to the second order approximation and $w\left(h_{i}, k_{i}\right)$ a weighting function.

If the norm $B_{5}(u)$ is minimized with respect the partial derivatives included in formulae (4), the following linear equations systems is obtained

$$
\mathbf{A} D_{u}=\mathbf{b}
$$

where the $\mathbf{A}$ is a matrix of $5 \times 5$, the vector $\boldsymbol{D}_{u}$ is given by

$$
D_{u}=\left\{\frac{\partial u_{0}}{\partial x}, \frac{\partial u_{0}}{\partial y}, \frac{\partial^{2} u_{0}}{\partial x^{2}}, \frac{\partial^{2} u_{0}}{\partial y^{2}}, \frac{\partial^{2} u_{0}}{\partial x \partial y}\right\}^{T}
$$

and $\mathbf{b}$ is the vector of independent terms, including the values $u_{0}, u_{i}(i=1, . ., N)$ to be solved by using $(\mathrm{GFDM})$ as described $[4,5]$ and $[6,7]$.

As the matrix of coefficients $\mathbf{A}$ is symmetrical, it is then possible to use the Cholesky method to solve the same (5). On solving the system (5), the explicit differences formulae are obtained $[4,5]$.

On including in the equation (1) the explicit expressions obtained for the partial derivatives, the star equation (7) is obtained as

$$
\lambda_{0} u_{0}+\sum_{i=1}^{N} \lambda_{i} u_{i}=f\left(x_{0}, y_{0}\right) \Leftrightarrow u_{0}=\sum_{i=1}^{N} m_{i} u_{i}+m_{f} f, \text { with } \sum_{i=1}^{N} m_{i}=1
$$




\section{A posteriori error indicator in the generalized finite differences}

It is possible to take more terms of the Taylor series expansion to obtain the approximate value of the function in any node of the star. The difference between the fourth order and the second order approximations in each node of the star, is:

$$
\begin{gathered}
{\left[u_{i}\right]_{\text {order } 4}-\left[u_{i}\right]_{\text {order } 2}=\frac{1}{6}\left(\frac{\partial^{3} u_{0}}{\partial x^{3}}+\frac{\partial^{3} u_{0}}{\partial y^{3}}+3 \frac{\partial^{3} u_{0}}{\partial x^{2} \partial y}+3 \frac{\partial^{3} u_{0}}{\partial x \partial^{2} y}\right)+\frac{1}{24}\left(\frac{\partial^{4} u_{0}}{\partial x^{4}}\right.} \\
\left.+\frac{\partial^{4} u_{0}}{\partial y^{4}}+4 \frac{\partial^{4} u_{0}}{\partial x^{3} \partial y}+6 \frac{\partial^{4} u_{0}}{\partial x^{2} \partial y^{2}}+4 \frac{\partial^{4} u_{0}}{\partial x \partial y^{3}}\right)
\end{gathered}
$$

The expression(8) is valid for $i=1, \cdots, N$, where $N$ is the number of nodes of the star. Of the other hand, the star equation (7) indicates that the value of the function at the central node of the star, is the weighting average of the function values at the rest of nodes, plus the corresponding to the independent term of partial differential equation (1). The error at the central node of the star may then be approximated by the weighted addition of the absolute values involving the $3^{\text {rd }}$ and $4^{\text {th }}$ order partial derivatives terms:

$$
\begin{gathered}
\operatorname{Ind}\left(u_{0}\right)=\sum_{i=1}^{N} \mid m_{i}\left(\frac{1}{6}\left(\frac{\partial^{3} u_{0}}{\partial x^{3}}+\frac{\partial^{3} u_{0}}{\partial y^{3}}+3 \frac{\partial^{3} u_{0}}{\partial x^{2} \partial y}+3 \frac{\partial^{3} u_{0}}{\partial x \partial^{2} y}\right)+\frac{1}{24}\left(\frac{\partial^{4} u_{0}}{\partial x^{4}}\right.\right. \\
\left.\left.+\frac{\partial^{4} u_{0}}{\partial y^{4}}+4 \frac{\partial^{4} u_{0}}{\partial x^{3} \partial y}+6 \frac{\partial^{4} u_{0}}{\partial x^{2} \partial y^{2}}+4 \frac{\partial^{4} u_{0}}{\partial x \partial y^{3}}\right)\right) \mid+m_{f} f\left(x_{0} \cdot y_{0}\right)
\end{gathered}
$$

where the $3^{r d}$ and $4^{\text {th }}$ order partial derivatives are calculated using the values of $1^{\text {st }}$ and $2^{\text {nd }}$ order derivatives, that were calculated before with the explicit formulas of $D_{U}$ obtained in $[4,5]$ and

$$
\frac{\partial^{s} u_{0}}{\partial x^{q} \partial y^{r}}=\frac{\partial^{q}}{\partial x^{q}}\left(\frac{\partial^{r} u_{0}}{\partial y^{r}}\right)=\frac{\partial^{r}}{\partial y^{r}}\left(\frac{\partial^{q} u_{0}}{\partial x^{q}}\right)
$$

where $s=q+r, s=3,4$ and $q, r=0,1,2$.

In this paper $\operatorname{Ind}\left(u_{0}\right)$, equation (9), is denominated error indicator.

\section{A posteriori error estimator in the generalized finite differences}

The error indicator developed in the previous section is now compared with a posteriori error estimator based on Orkisz's works $[2,8,9]$.

Let us consider the fourth order Taylor approximation and, as in (4), it is possible to define a function $B[u]$, now involving partial derivatives until $4^{\text {th }}$ order. Minimizing $B[u]$ with respect the partial derivatives $D_{u}=\left\{\frac{\partial u_{0}}{\partial x}, \frac{\partial u_{0}}{\partial y}, \frac{\partial^{2} u_{0}}{\partial x^{2}}, \frac{\partial^{2} u_{0}}{\partial y^{2}}, \frac{\partial^{2} u_{0}}{\partial x \partial y}\right\}^{T}$, the following linear equations system is obtained

$$
\mathbf{A} \boldsymbol{D}_{u}+\boldsymbol{b}^{*}=\mathbf{b}
$$

being $\mathbf{A}, \boldsymbol{D}_{u}$, b the matrix and vectors considered in section 2 and $\boldsymbol{b}^{*}$ a new vector with the terms involving $3^{\text {rd }}$ and $4^{\text {th }}$ order partial derivatives. 
The equation (11) can be written as:

$$
\boldsymbol{D}_{u}+\boldsymbol{A}^{-1} \boldsymbol{b}^{*}=\boldsymbol{A}^{-1} \boldsymbol{b}
$$

where $\boldsymbol{A}^{-1} \boldsymbol{b}$ correspond to the second order approximation (it can be substituted by the explicit differences formulae obtained from (5)).

We can call these $u_{0}^{(4)}$ y $u_{i}^{(4)}$ to the fourth order approximations at the central node and the rest of the star nodes respectively, and $\triangle u_{0}$ y $\triangle u_{1}$ to the errors, at the same nodes, between the fourth and second order approximations. The bearing in mind the principles of linearity in the solution and superposition, we can write:

$$
u_{0}^{(4)}=u_{0}+\triangle u_{0} ; \quad u_{i}^{(4)}=u_{i}+\triangle u_{i}
$$

We can also write (1) as:

$$
\boldsymbol{\alpha} \boldsymbol{D}_{u}=f(x, y)
$$

where $\boldsymbol{\alpha}$ is the vector of coefficients of the equation (1), $\boldsymbol{\alpha}=\left\{\begin{array}{lllll}\alpha_{1} & \alpha_{2} & \alpha_{3} & \alpha_{4} & \alpha_{5}\end{array}\right\}$.

If we substitute $\boldsymbol{D}_{u}$, obtained from (12), for each node of domain, into equation (14), we obtain:

$$
\boldsymbol{\alpha}\left(\boldsymbol{A}^{-1} \boldsymbol{b}-\boldsymbol{A}^{-1} \boldsymbol{b}^{*}\right)=f\left(x_{0}, y_{0}\right)=\lambda_{0} u_{0}^{(4)}+\sum_{i=1}^{N} \lambda_{i} u_{i}^{(4)}
$$

According to section 2, we can write:

$$
\boldsymbol{\alpha} \boldsymbol{A}^{-1} \boldsymbol{b}=\lambda_{0} u_{0}+\sum_{i=1}^{N} \lambda_{i} u_{i}
$$

substituting the values of $u_{0}^{(4)}$ y $u_{i}^{(4)}$ given in (13) into equation (15), considering (16) and after operations, we have:

$$
\lambda_{0} \triangle u_{0}+\sum_{i=1}^{N} \lambda_{i} \triangle u_{i}=-\boldsymbol{\alpha} \boldsymbol{A}^{-1} \boldsymbol{b}^{*}
$$

The expression (17) is the star equation for the calculus of a estimation of the error at the nodes of the star.

If we apply (17) to the nodes of the domain, we obtain a system of equations in which the matrix of coefficients is the one obtained in section 2 for the second order approximation and in the vector of independent terms are expressions including third and fourth partial derivatives in the central node of the star. We can obtain these values as we mentioned in section 3.

In this method it is necessary to solve the system of equations twice, and also to obtain the third and fourth order derivatives, for which the method will need more time than the explained in section 3. In this paper, $\triangle u_{i}$, obtained solving equation (17), is denominated error estimator.

\section{An h-adaptive method}

By using the posteriori error indicator as proposed in section 2, it is possible to find an algorithm to improve the approximation solution by selectively increasing the number of nodes in the domain.

In the stars whose central node had an error (obtained using the posteriori error indicator) greater than a 


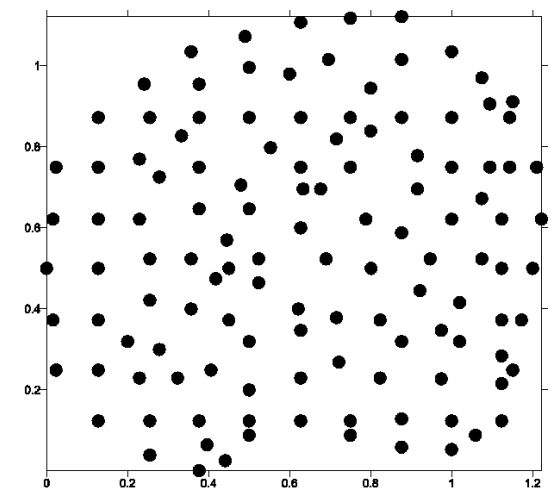

Fig. 1. First cloud of 122 nodes

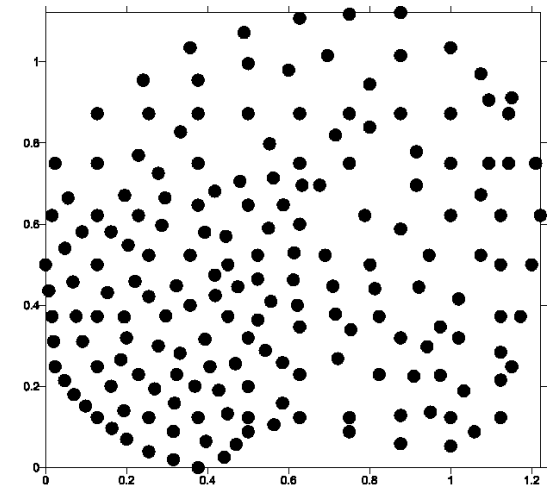

Fig. 2. Last cloud of 181 nodes

fixed value, new nodes would be added to the centre of gravity of the triangles made using the central node and the others nodes of each star one after the other to avoid overlapping of the triangles. In addition, some nodes are added to the boundary.

In order to avoid misleading clouds, a limit for the distance between nodes is used as a parameter (minimum distance) of the h-adaptive method, in such a way that if the distance between the new node and any node of the domain is smaller than this minimum distance, then, the new node should not be added. This minimum distance is given as the maximum distance between all nodes of the mesh, multiplied by a positive parameter $\alpha<1$.

\section{Numerical results}

This section includes an example to illustrate the different results obtained for both posteriori error approximations and the application of h-adaptive method.

In this section both posteriori error approximations are used to solve various second order partial differential equations, with the objective of first comparing the indicator error approximations with estimator error approximations and subsequently to apply the adaptive algorithm.

\subsection{Example 1}

Application to solve Laplace equation, with Dirichlet boundary condition and the exact solution is $U(x, y)=L\left(x^{2}+y^{2}\right)$ and the weighting function

$$
\omega(x, y)=\frac{1}{(d i s t)^{3}}
$$

where dist is the distance between the central node and the considered node in star. The domain is defined by figure 2 (mesh with 181 nodes).

The first cloud, figure 1, has 122 nodes (30 nodes in the boundary) and after two adaptive steps we obtain the cloud showed in figure 2, which has 181 nodes (40 nodes in the boundary, ten nodes more that the first clouds, included in the side with greater error).

Figures 3,4,5 show the absolute exact error and the error approximations of the solutions for each interior node (value multiplied by $10^{3}$ ) (using for representation Modified Shepard's Method) using the indicator and estimator previously described for the last step (cloud of nodes of figure 2).

In table 1 we can see a summary of the global errors obtained using the adaptive method. In this table 


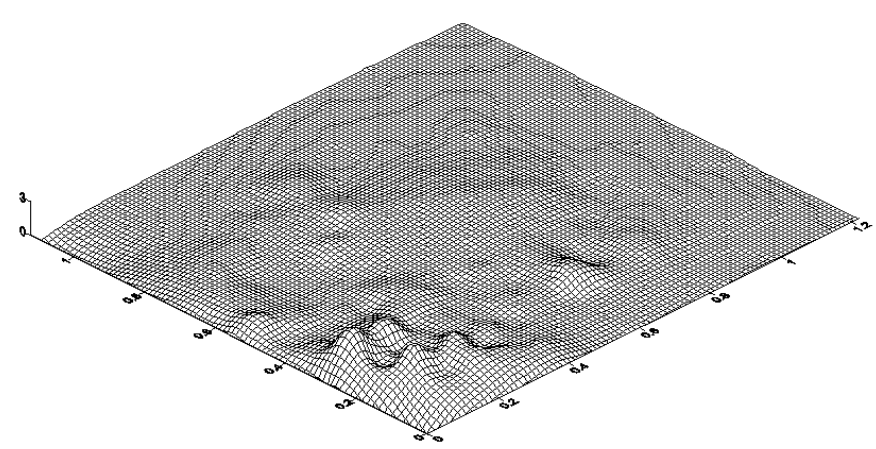

Fig. 3 Cloud of 181 nodes. Absolute error
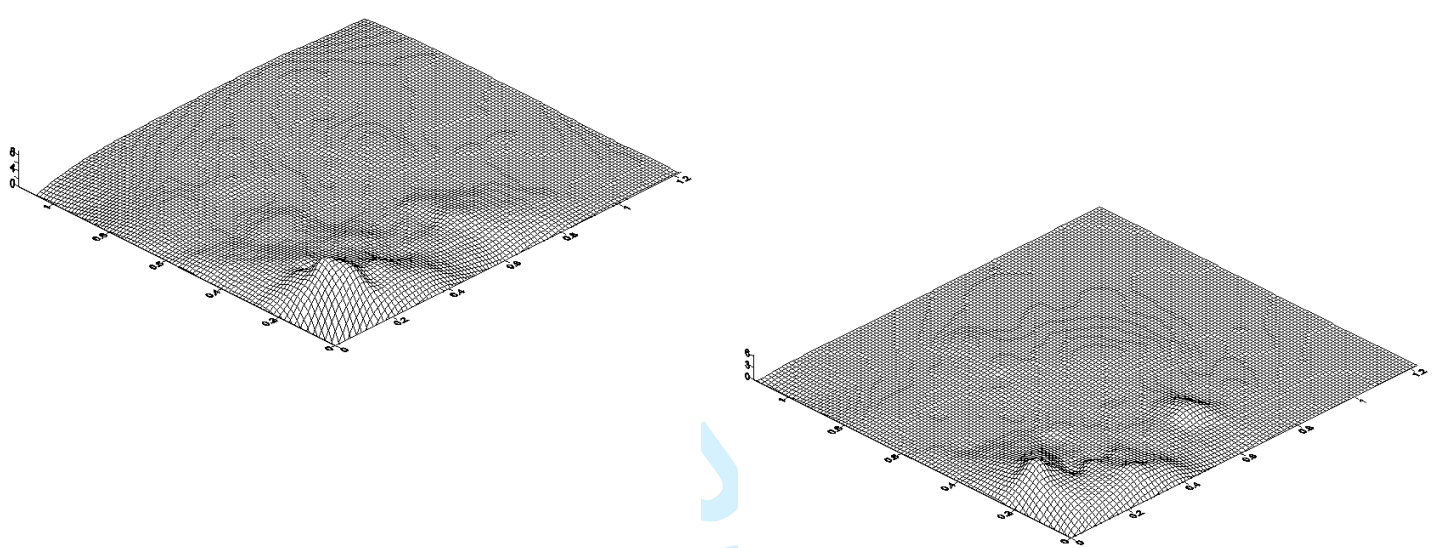

Fig. 4 Cloud of 181 nodes. Indicator error Fig. 5 Cloud of 181 nodes. Estimator error

the global error is:

$$
\text { Global } \quad \text { error }=\frac{\sqrt{\frac{\sum_{i=1}^{N} e_{i}^{2}}{N}}}{e x a c_{\max }}
$$

where $N$ is the number of nodes in the domain, $e x a c_{\max }$ is the maximum exact value of function in the domain, $e_{i}$ is the error in the node $i$. The first column includes exact error value, $e_{i}=\operatorname{sol}(i)-\operatorname{exac}(i)$; the second column, the error indicator value $e_{i}=\operatorname{Ind}\left(u_{i}\right)$ and the last one, the error estimator value, $e_{i}=\Delta u_{i}$.

\begin{tabular}{|l|c|r|r|}
\hline \multicolumn{4}{|c|}{ Global error } \\
\hline Number of nodes & Exact error & using indicator & using estimator \\
\hline 122 & 0.3148 & 0.1938 & 1.2231 \\
\hline 141 & 0.0392 & 0.0821 & 0.0614 \\
\hline 181 & 0.0198 & 0.0485 & 0.0349 \\
\hline
\end{tabular}

Table 1. Adaptive Method. Global errors.

Figures 6 and 7 show the absolute errors, $\left|e_{i}\right|=|\operatorname{sol}(i)-\operatorname{exac}(i)|$, in the nodes of domain, vertical lines, for the step 1 (cloud of 122 nodes) and for the last step (cloud of 181 nodes) respectively, as it is shown 


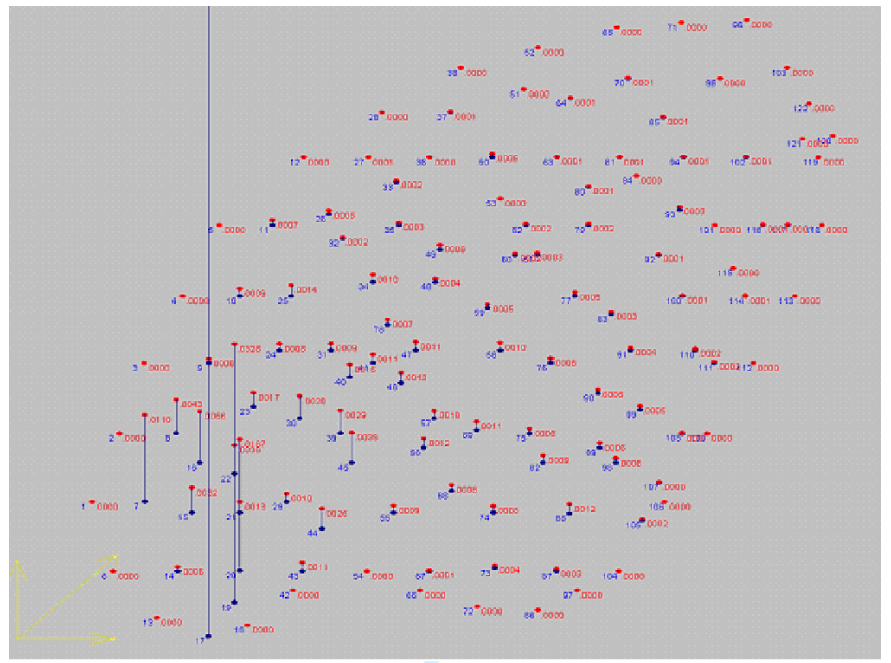

Fig.6. Absolute error (122 nodes).

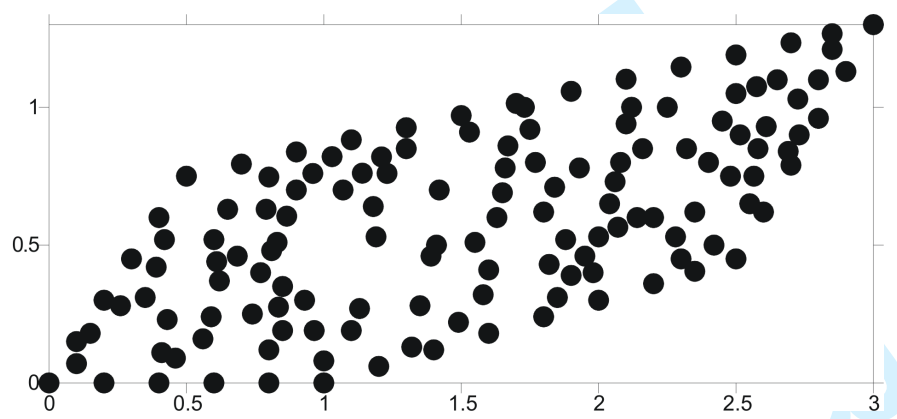

Fig. 8. First cloud of 136 nodes

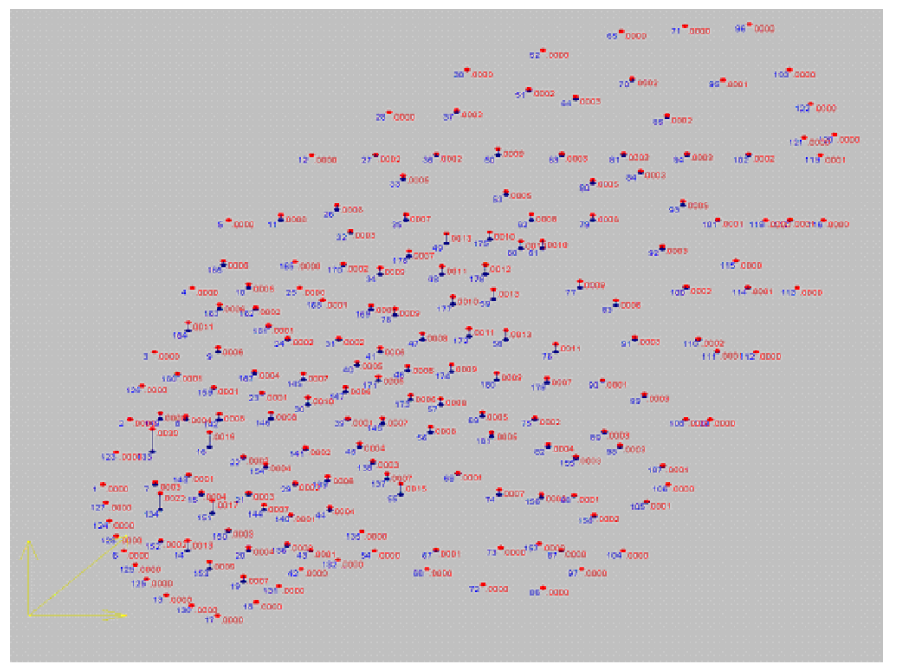

Fig.7. Absolute error (181 nodes).

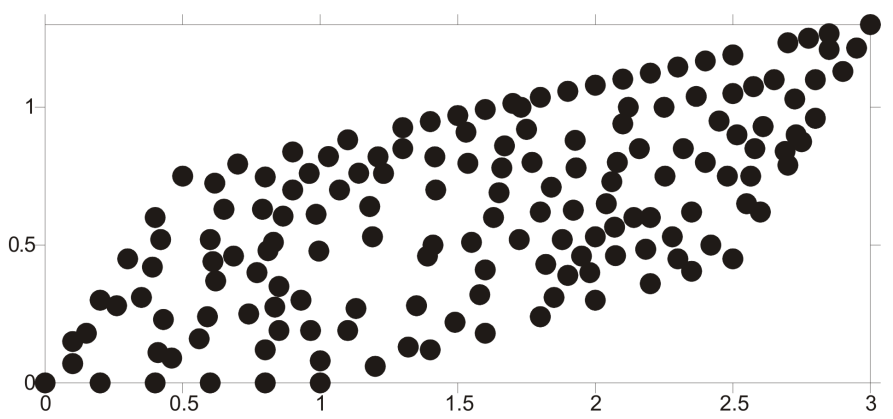

Fig. 9. Last cloud of 157 nodes

in figure 7 the error at the nodes of the domain decrease.

\section{2. $\quad$ Example 2}

Application to solve the equation

$$
\frac{\partial^{2} U}{\partial x^{2}}+\frac{\partial^{2} U}{\partial x \partial y}+\frac{\partial^{2} U}{\partial y^{2}}-\frac{\partial U}{\partial x}-\frac{\partial U}{\partial y}=0
$$

with Dirichlet boundary condition and the exact solution is

$$
U(x, y)=y e^{x}
$$

using the weighting function (18). The domain is defined by figure 8 (mesh with 136 nodes).

The first cloud, figure 8, has 136 nodes (36 nodes in the boundary) and after three steps we obtain the cloud showed in figure 9, which has 157 nodes (45 nodes in the boundary, nine nodes more that the first clouds, included in the side with greater error).

Figures 10,11, 12 show the absolute exact error and the error approximations of the solutions for each interior node (value multiplied by $10^{2}$ ) (using for representation Modified Shepard's Method) using the indicator and estimator previously described for the last step (mesh of 9).

In table 2 we can see a summary of the global errors obtained using the adaptive method 


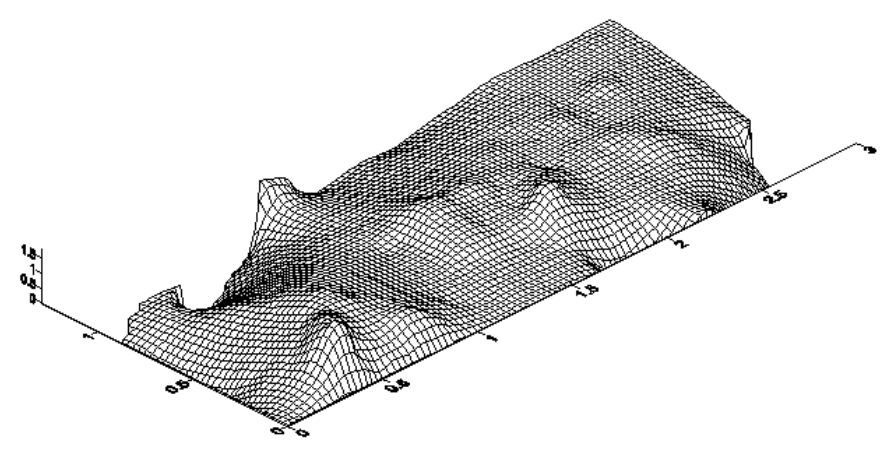

Fig. 10 Cloud of 157 nodes. Absolute error
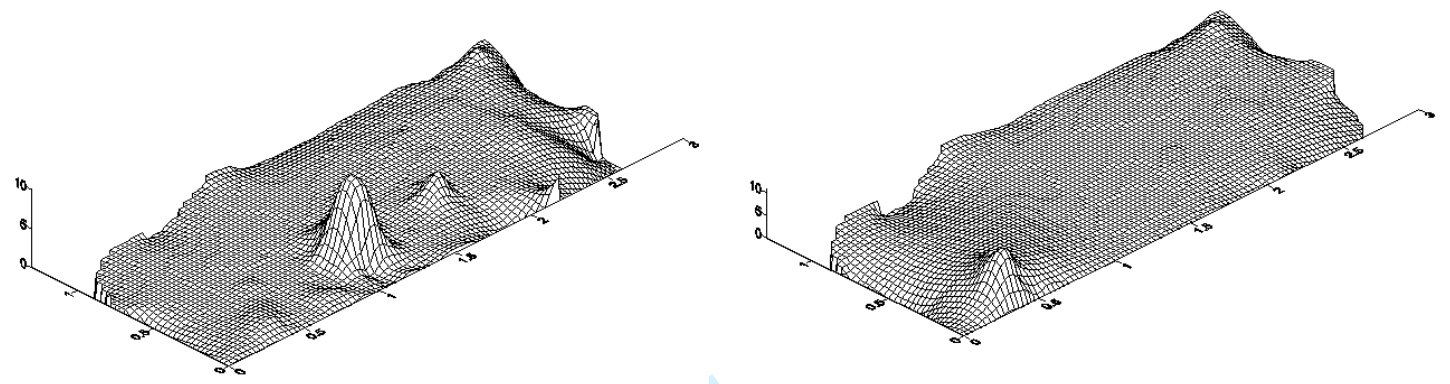

Fig. 11 Cloud of 157 nodes. Indicator error Fig. 12 Cloud of 157 nodes. Estimator error

\begin{tabular}{|l|c|r|r|}
\hline \multicolumn{4}{|c|}{ Global error } \\
\hline Number of nodes & Exact error & using indicator & using estimator \\
\hline 136 & 0.057 & 0.0397 & 0.0297 \\
\hline 146 & 0.0244 & 0.0393 & 0.0277 \\
\hline 150 & 0.0144 & 0.0232 & 0.0192 \\
\hline 157 & 0.0124 & 0.0217 & 0.0172 \\
\hline
\end{tabular}

Table 2. Adaptive Method. Global errors.

Figures 13 and 14 show the absolute errors in the nodes of domain for the step 1 (cloud of 136 nodes) and for the last step (cloud of 157 nodes) respectively, as it is shown in figure 14 the error at the nodes of the domain decrease.

\section{Conclusions}

The comparison of the results obtained using both error approximations, shows a similar efficiency. But the error indicator uses less time to get the solution since it does not need to solve the system of equations again.

The use of the error indicator and the adaptive method allows us to decrease global and local errors significantly. If we compare the results obtained here with the others obtained previously [5], it's important to add nodes looking for an improvement in the regularity of the mesh. 
1

2

3

4

5

6

7

8

9

10

11

12

13

14

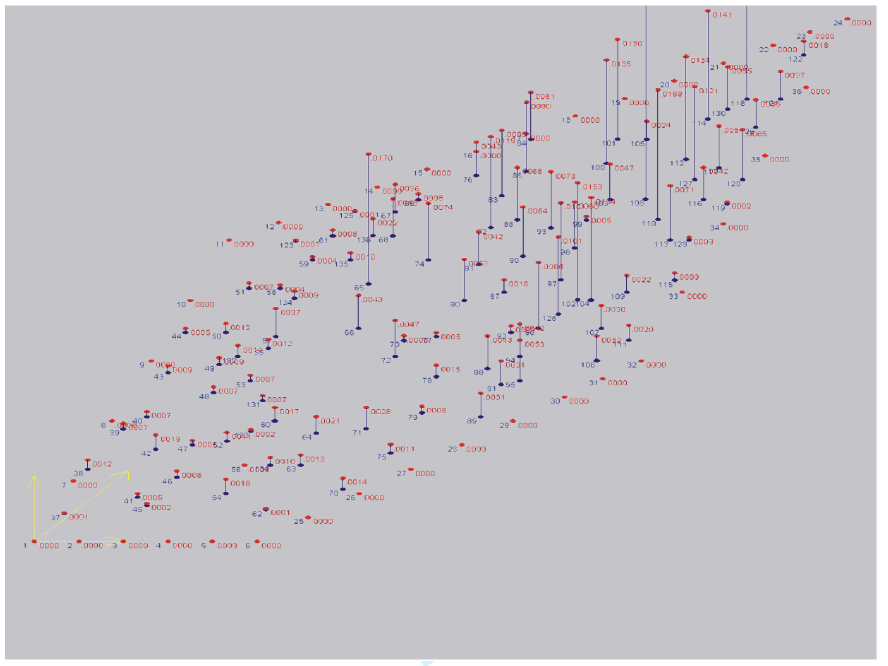

Fig.13. Absolute error (136 nodes).

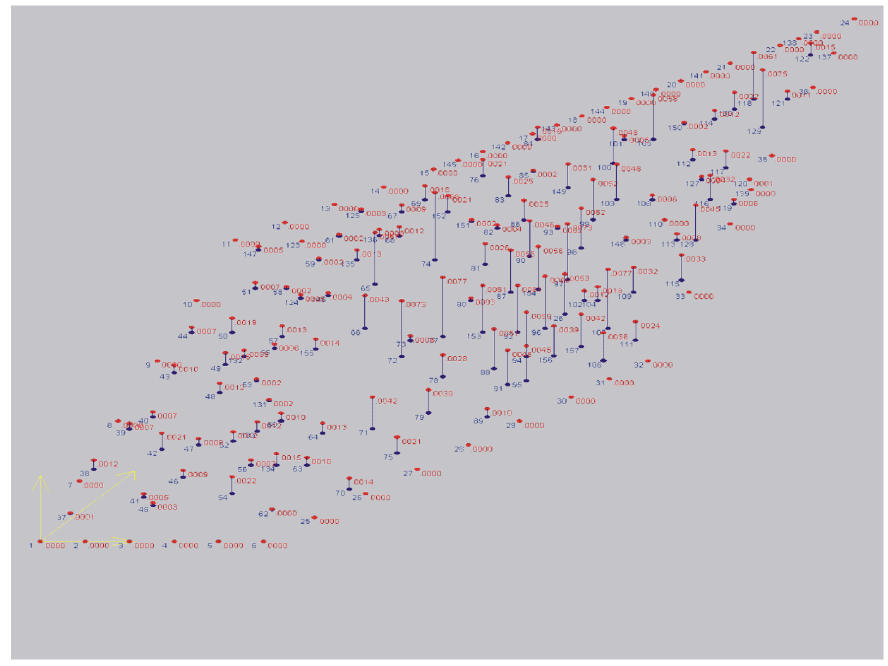

Fig.14. Absolute error (157 nodes).

\section{Acknowledgements}

The authors acknowledge the support from Ministerio de Educación y Ciencia of Spain, project CGL200404095/CLI, and the support from Consejería de Educación y Ciencia de la Junta de Comunidades de Castilla-La Mancha of Spain, project PA106 - 0123 - 7821.

\section{References}

[1] G.R. Liu, Mesh Free Methods, C.R.C, 2003.

[2] J. Orkisz, Handbook of Computational Solid Mechanics. Finite Difference Method (Part III), M. Kleiber (Ed) Springer-Verlag, Berlin, 1998.

[3] T. Belystscho, Y. Krouganz, D. Organ, M.Fleming and P. Krysl, "Meshless Methods: an overview and recent developments", Comput. Methods Appl. Mech. Eng. 139 (1996) 3-47.

[4] J.J. Benito, F. Urena, L. Gavete, "Influence of several factors in the generalized finite difference method", Applied Mathematical Modelling 25 (2001) 1039-1053.

[5] J.J. Benito, F. Urena, L. Gavete, R. Alvarez, "An h-adaptive method in the generalized finite differences", Comput. Methods Appl. Mech. Engrg. 192 (2003) 735-759.

[6] T. LiszKA, "An interpolation method for an irregular net of nodes", International Journal of Numerical Methods in Engineering. vol. 192 (1984) 1599-1612.

[7] T. LiszkA, J. Orkisz, "The finite difference method at arbitrary irregular grids and its application in applied mechanics", Computers \& Structures vol. II Pergamon Press (1980) 83-95.

[8] J. Orkisz, "Meshless finite difference method I. Basic approach", Computational Mechanics, Idelson, Onate, Duorkin (Eds), iacm, CINME (1998).

[9] J. Orkisz, "Meshless finite difference method II. Adaptive approach", Computational Mechanics, Idelson, Onate, Duorkin (Eds), iacm, CINME (1998).

[10] F. Urena, J.J. Benito, L. Gavete, R. Alvarez, "Computational Error Approximation and H-Adaptive Algorithm for the 3-D Generalized Finite Difference Method", International Journal for Computational Methods in Engineering Science and Mechanics 6 (2005) 31-39. 


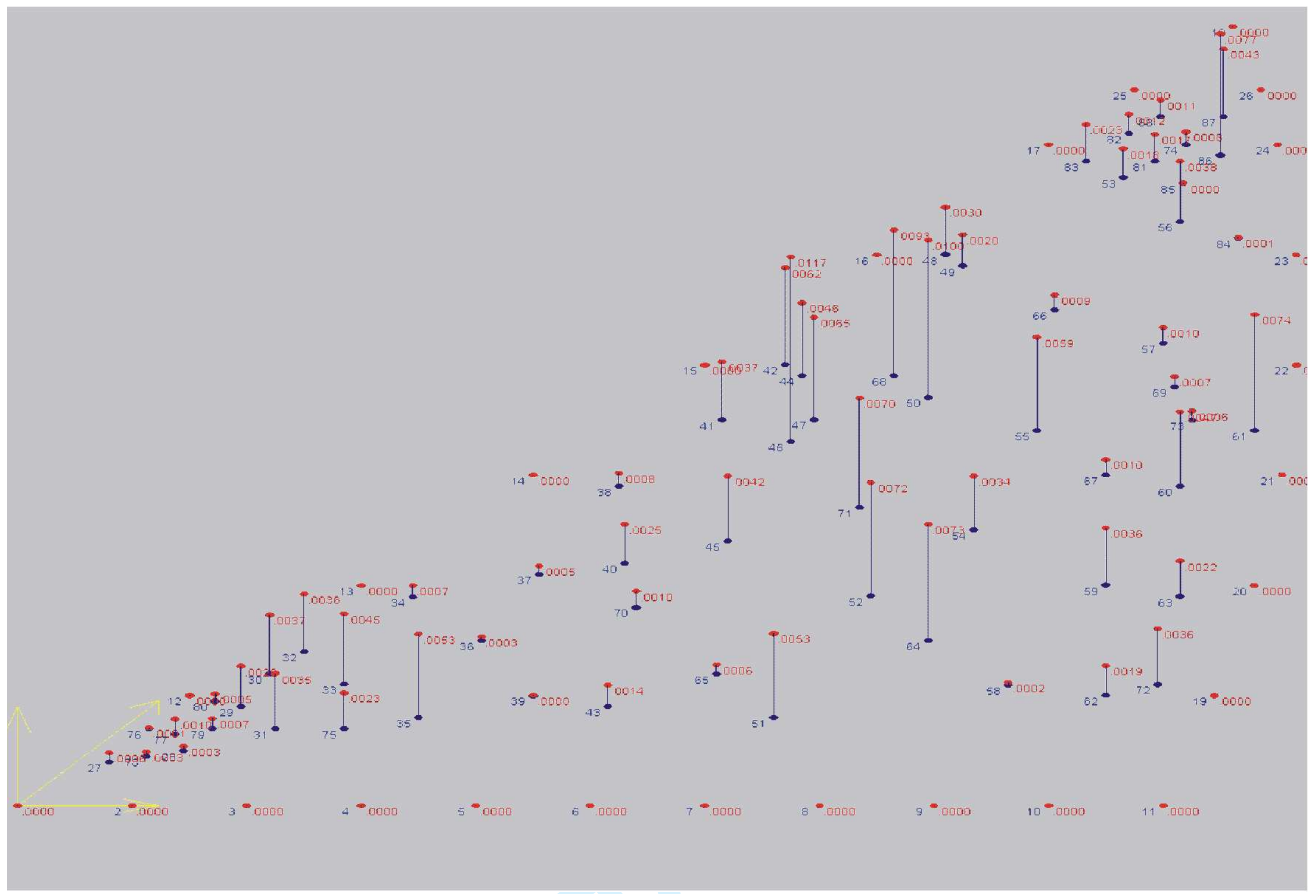




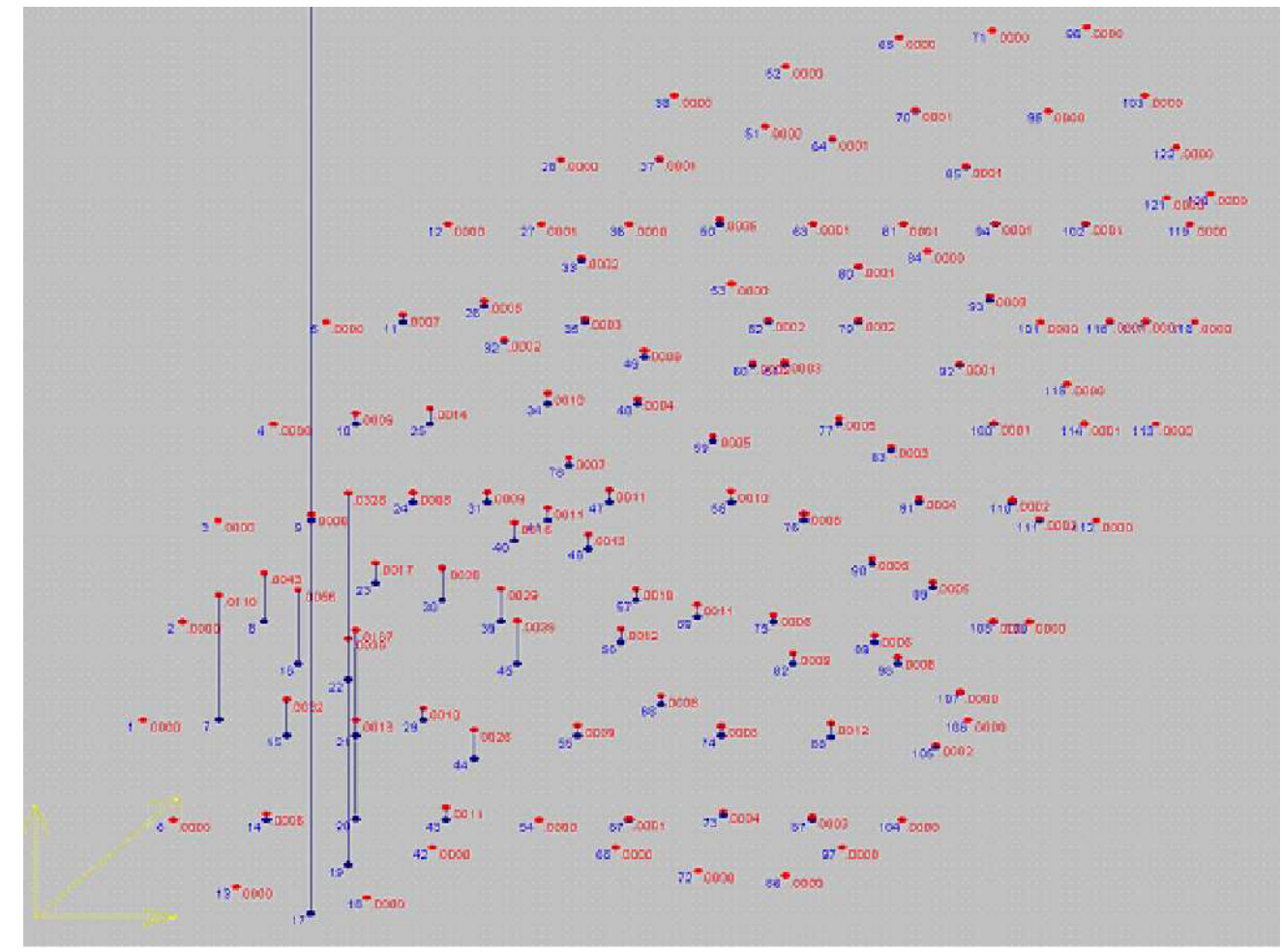

$355 \times 266 \mathrm{~mm}(72 \times 72$ DPI $)$ 


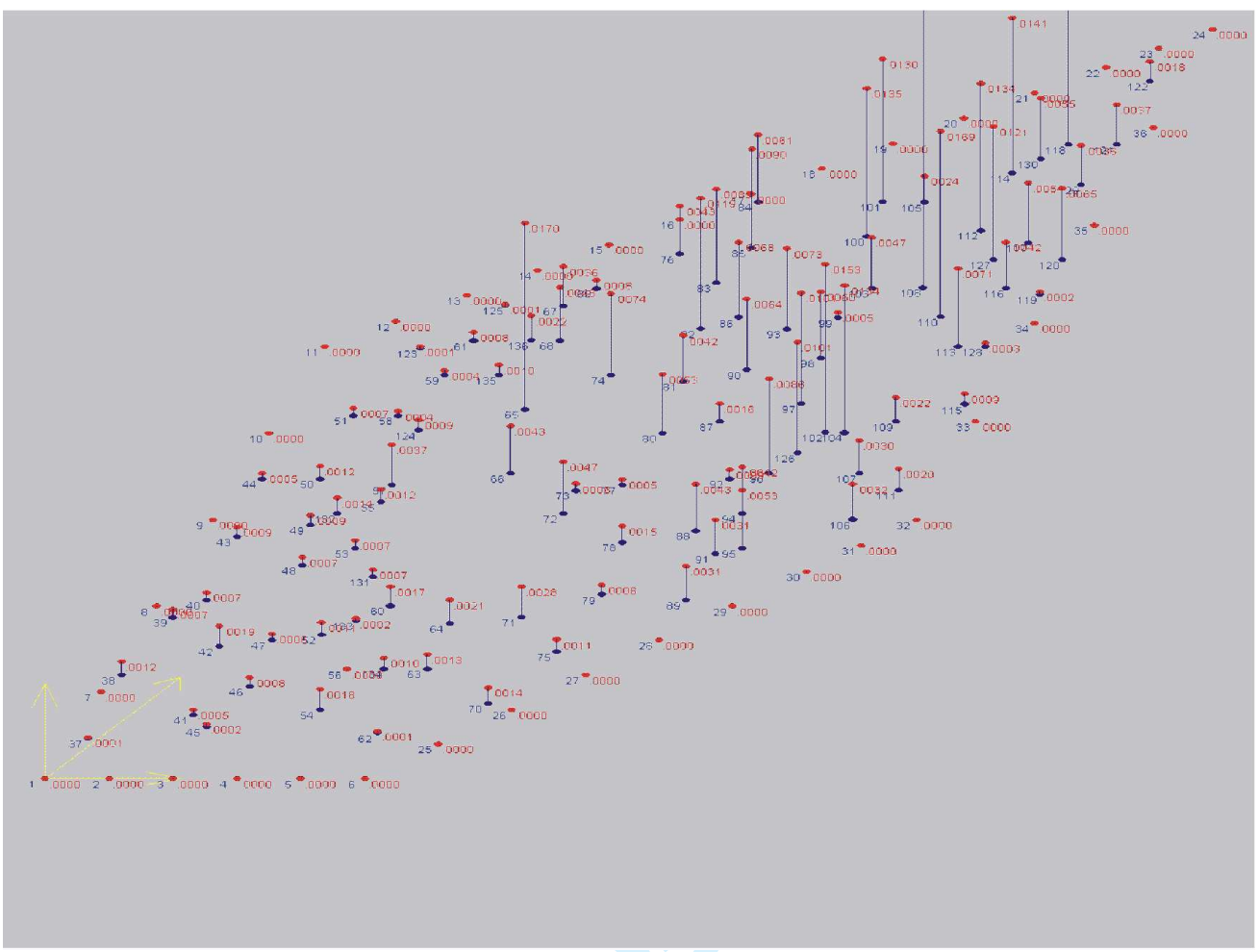




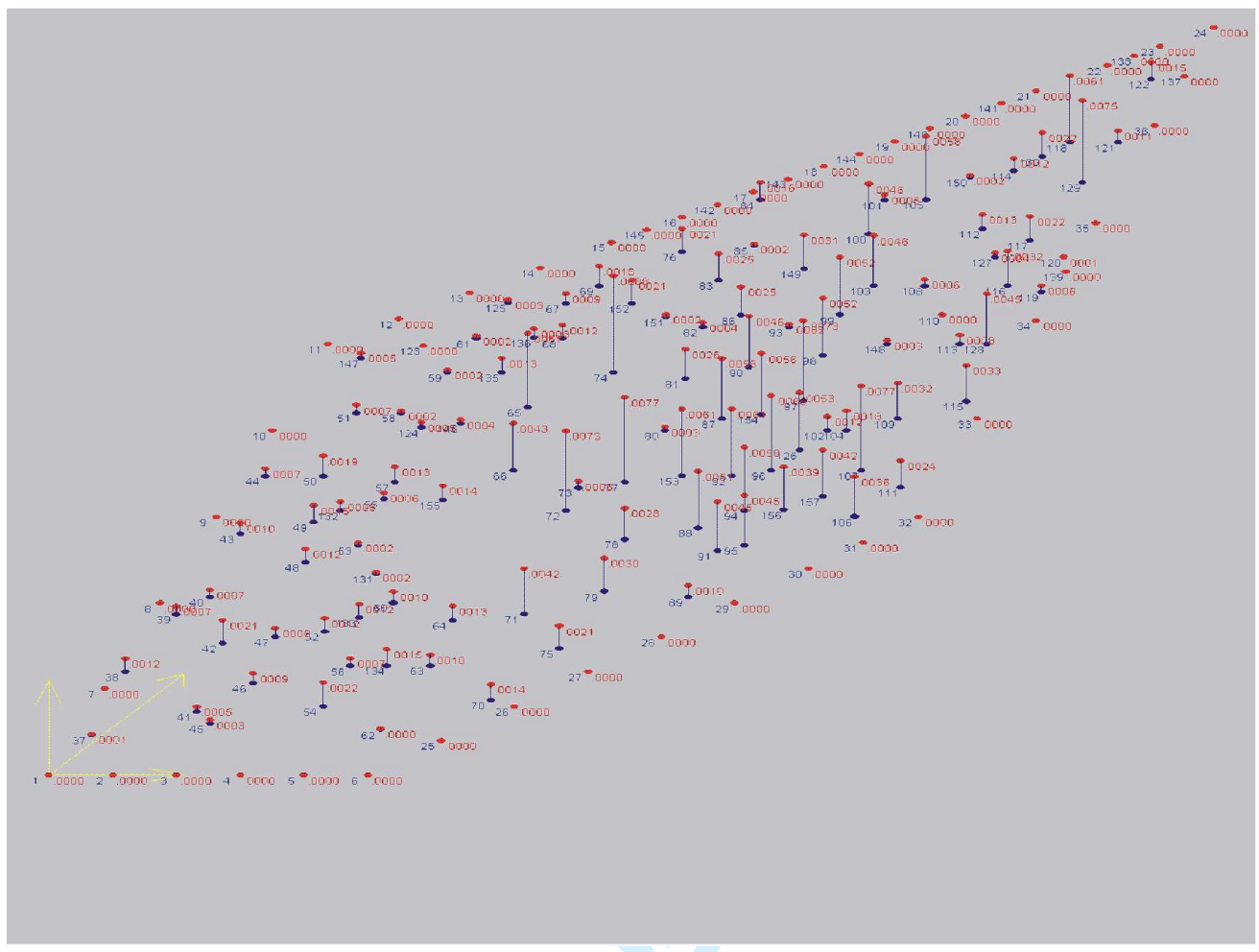




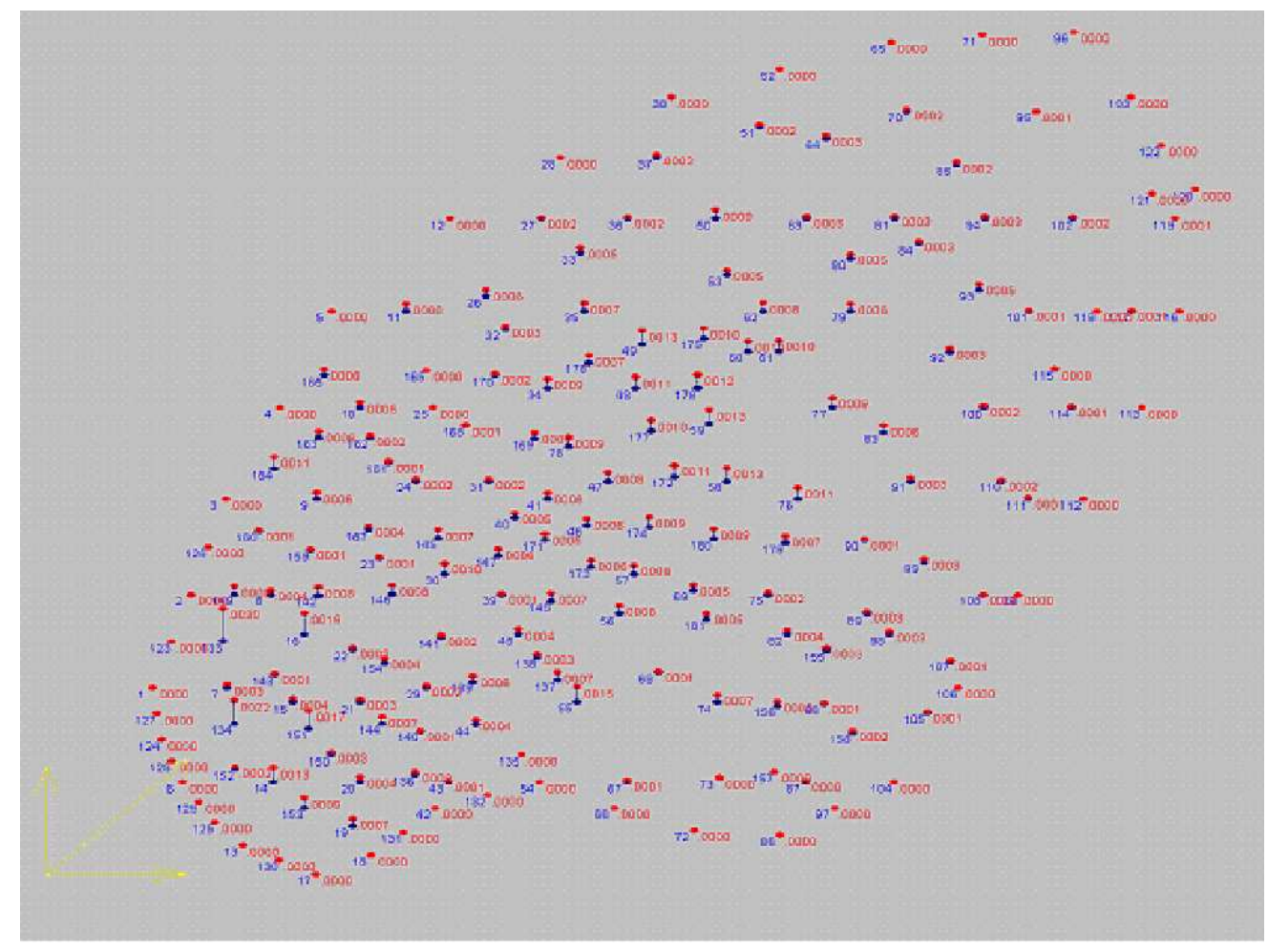

$355 \times 266 \mathrm{~mm}(72 \times 72 \mathrm{DPI})$ 


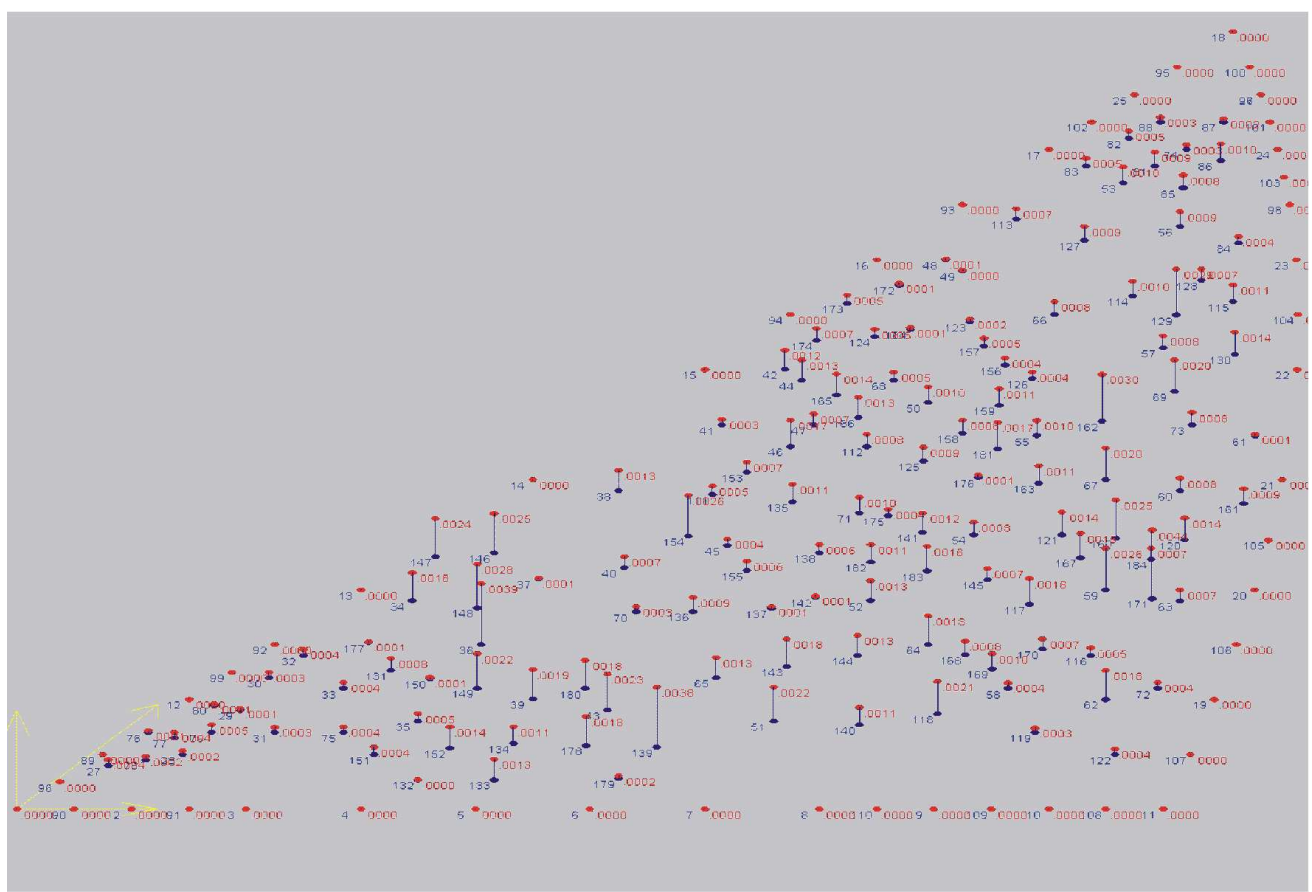




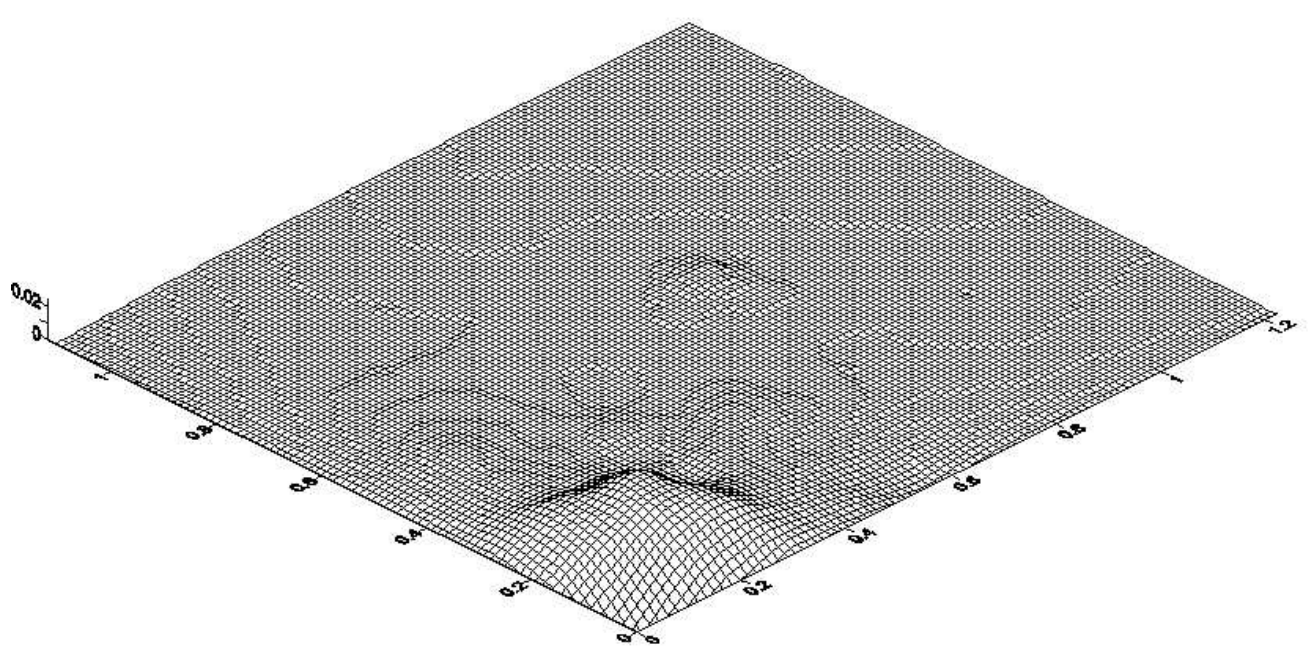

$292 \times 181 \mathrm{~mm}(72 \times 72$ DPI $)$ 


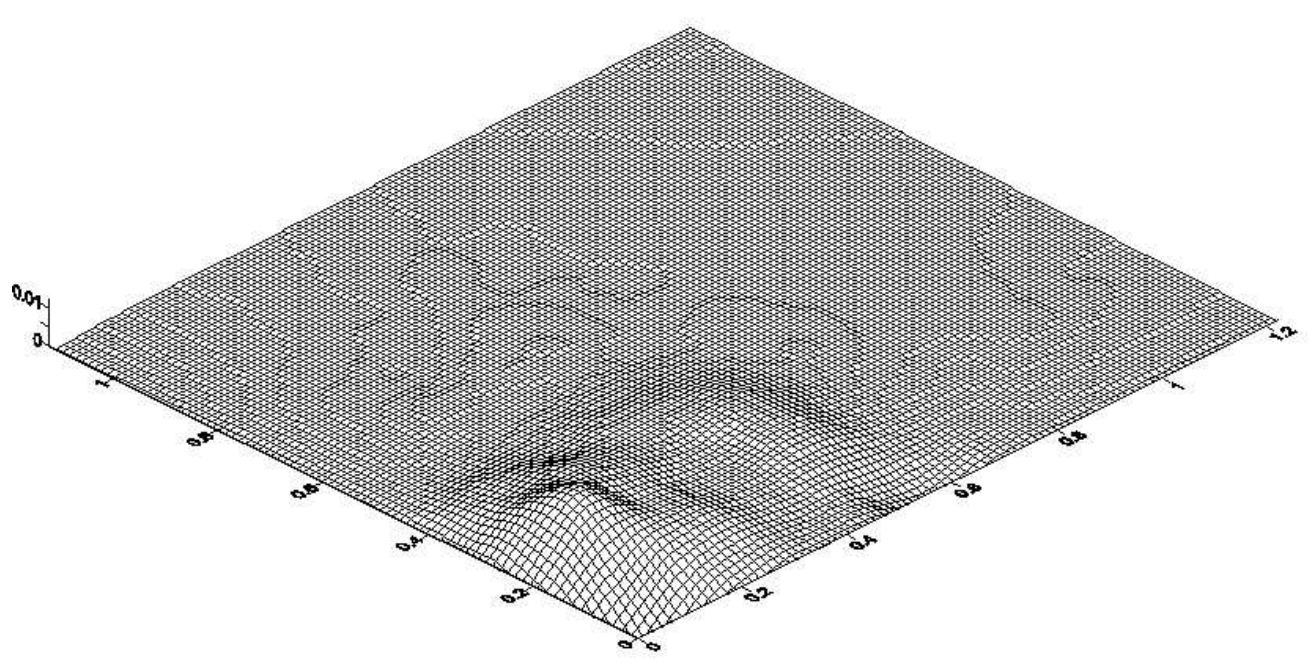

$292 \times 181 \mathrm{~mm}(72 \times 72 \mathrm{DPI})$ 


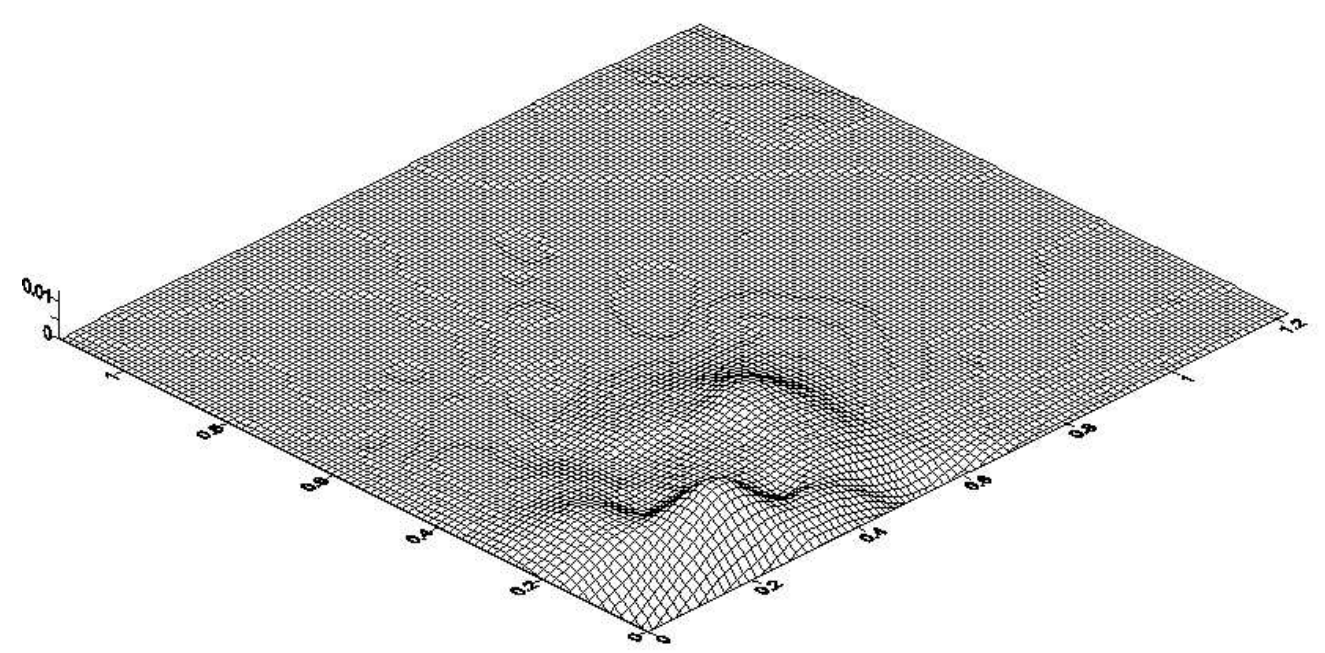

$292 \times 181 \mathrm{~mm}(72 \times 72 \mathrm{DPI})$ 


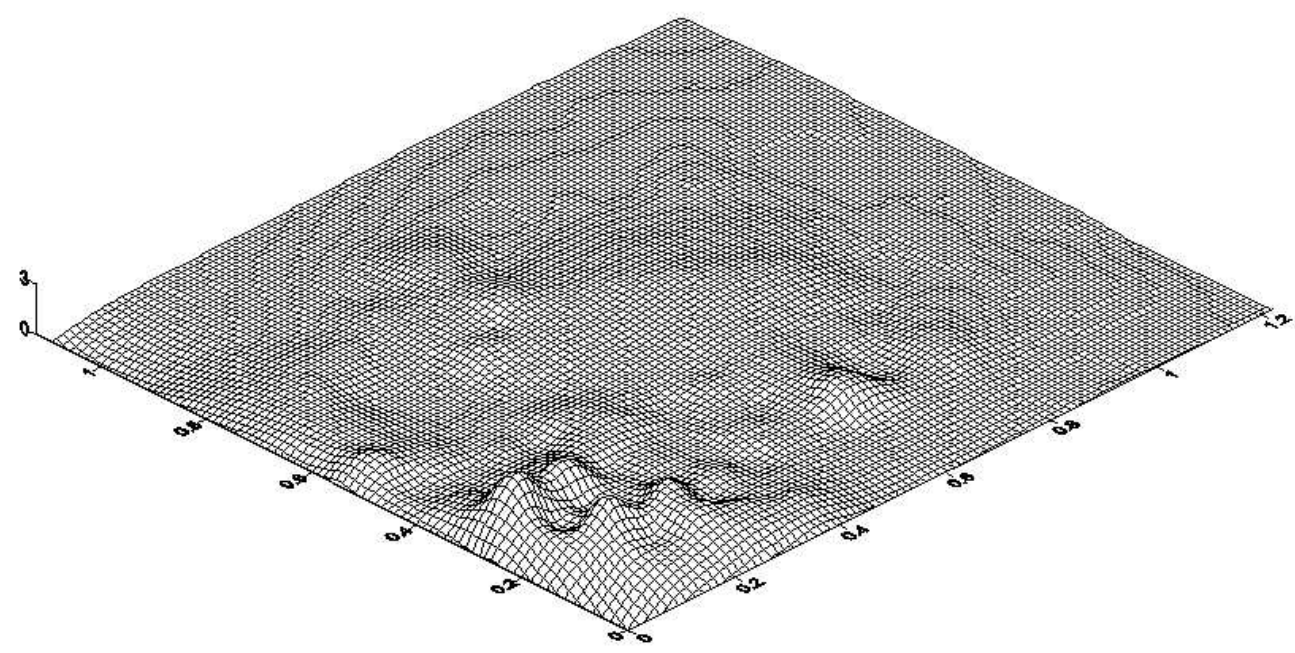

$289 \times 181 \mathrm{~mm}(72 \times 72 \mathrm{DPI})$ 


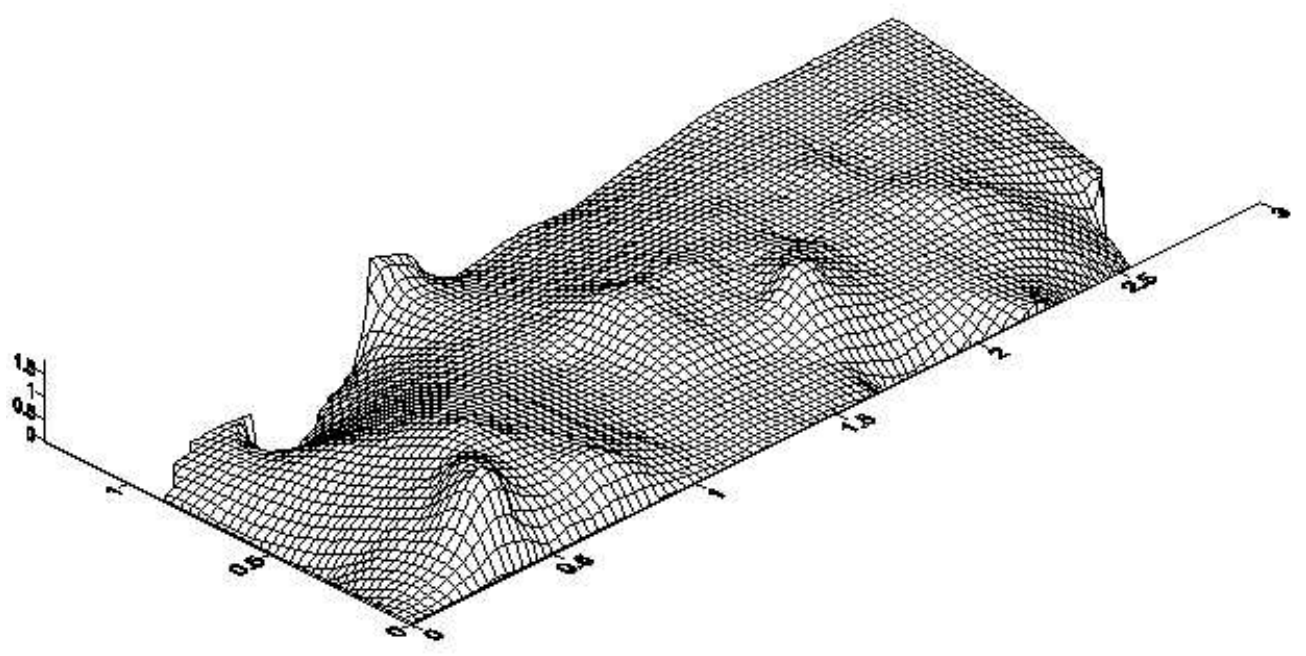

$220 \times 146 \mathrm{~mm}(72 \times 72 \mathrm{DPI})$ 


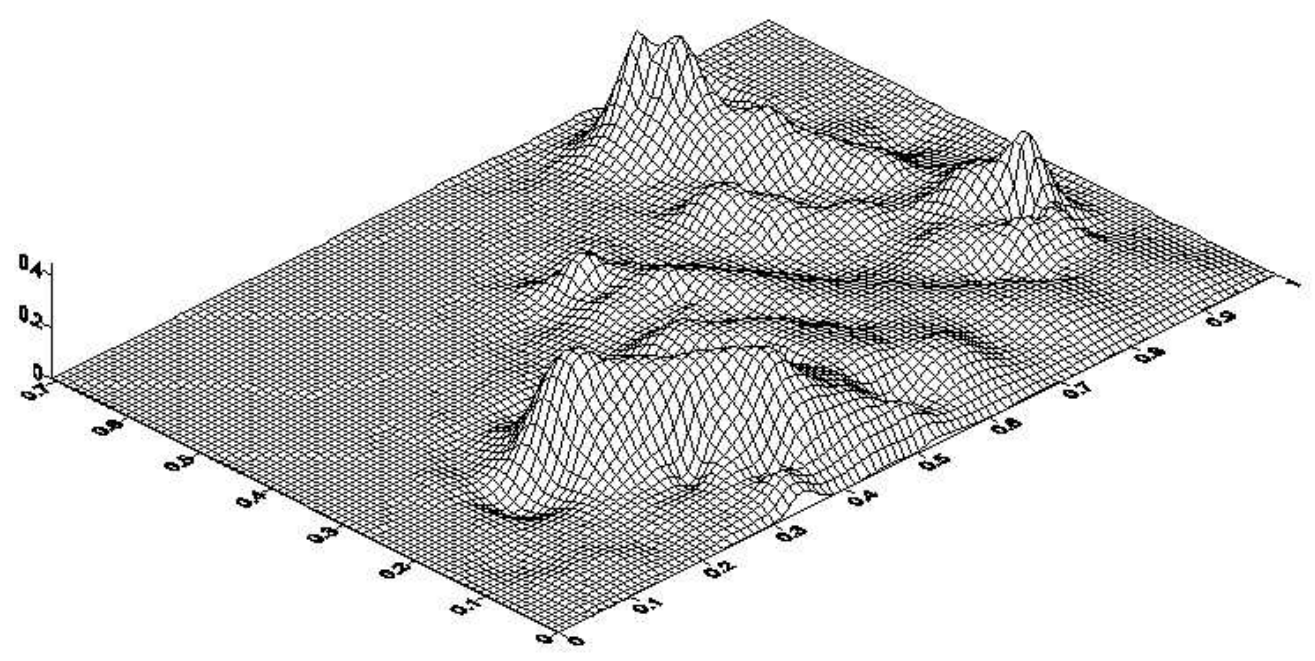

$260 \times 166 \mathrm{~mm}(72 \times 72$ DPI $)$ 


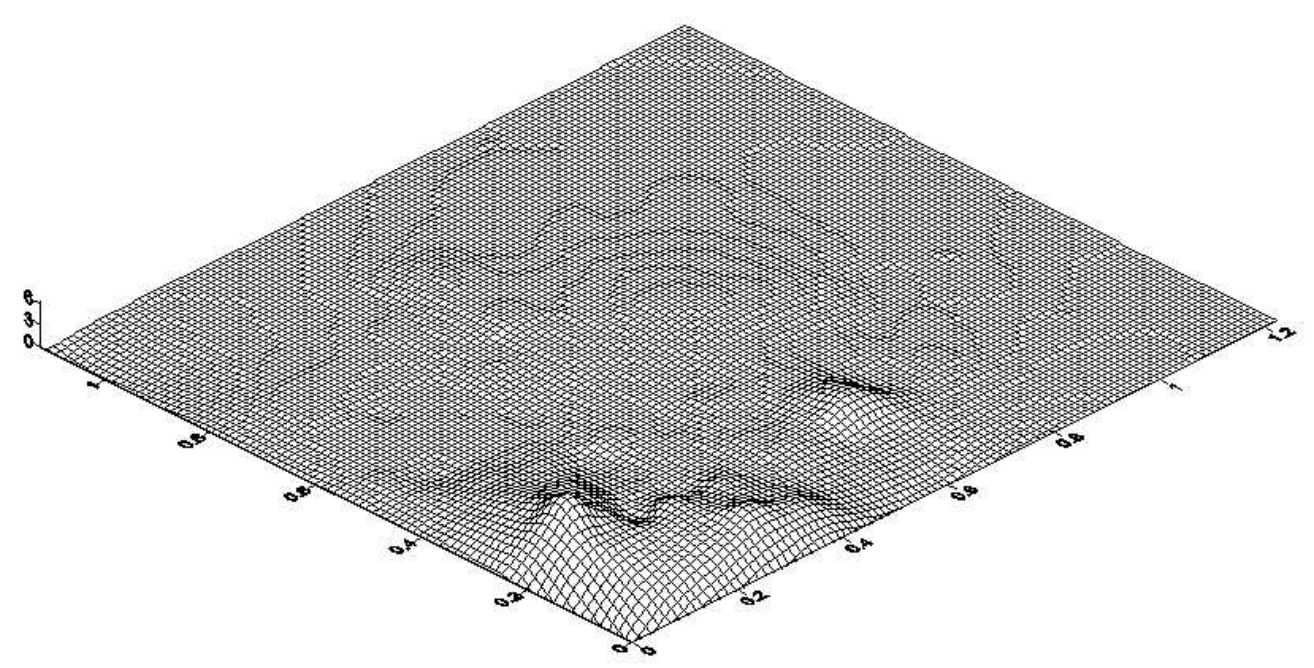

$289 \times 181 \mathrm{~mm}(72 \times 72 \mathrm{DPI})$ 


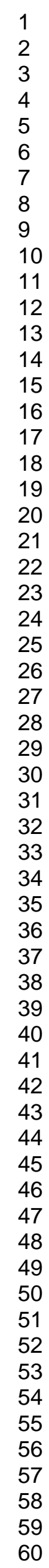

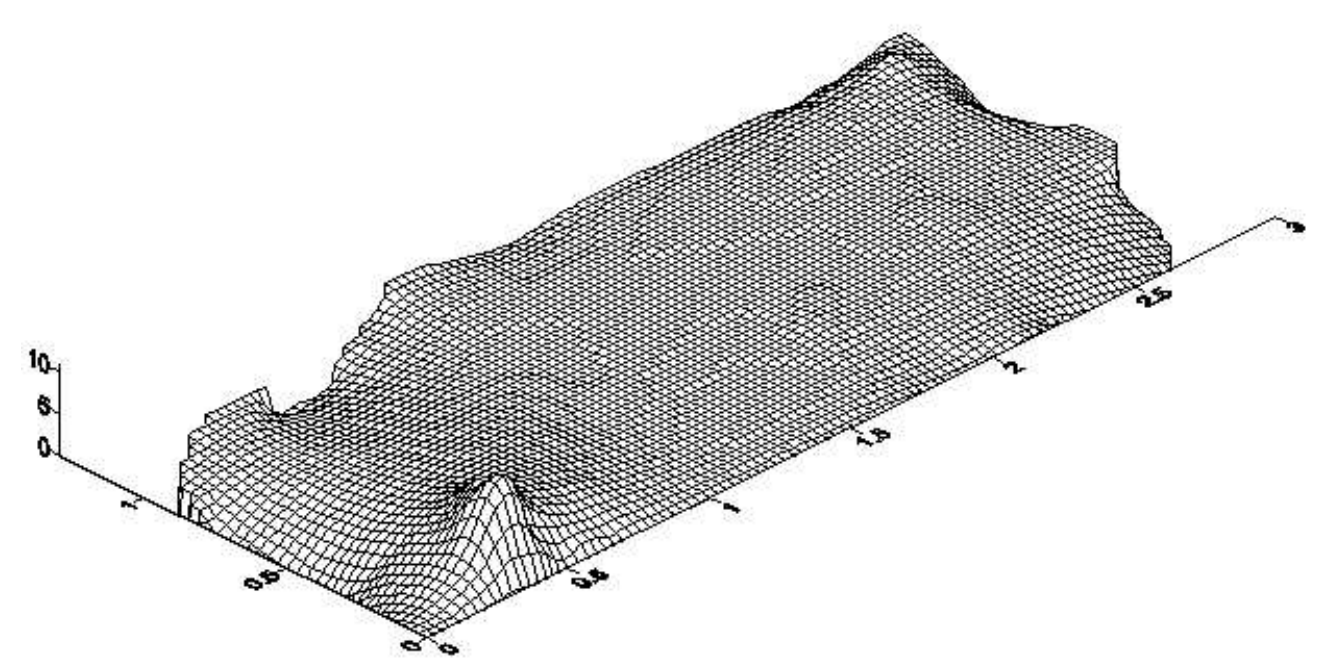

$220 \times 146 \mathrm{~mm}(72 \times 72 \mathrm{DPI})$

URL: http://mc.manuscriptcentral.com/gcom E-mail: ijcm@informa.com 


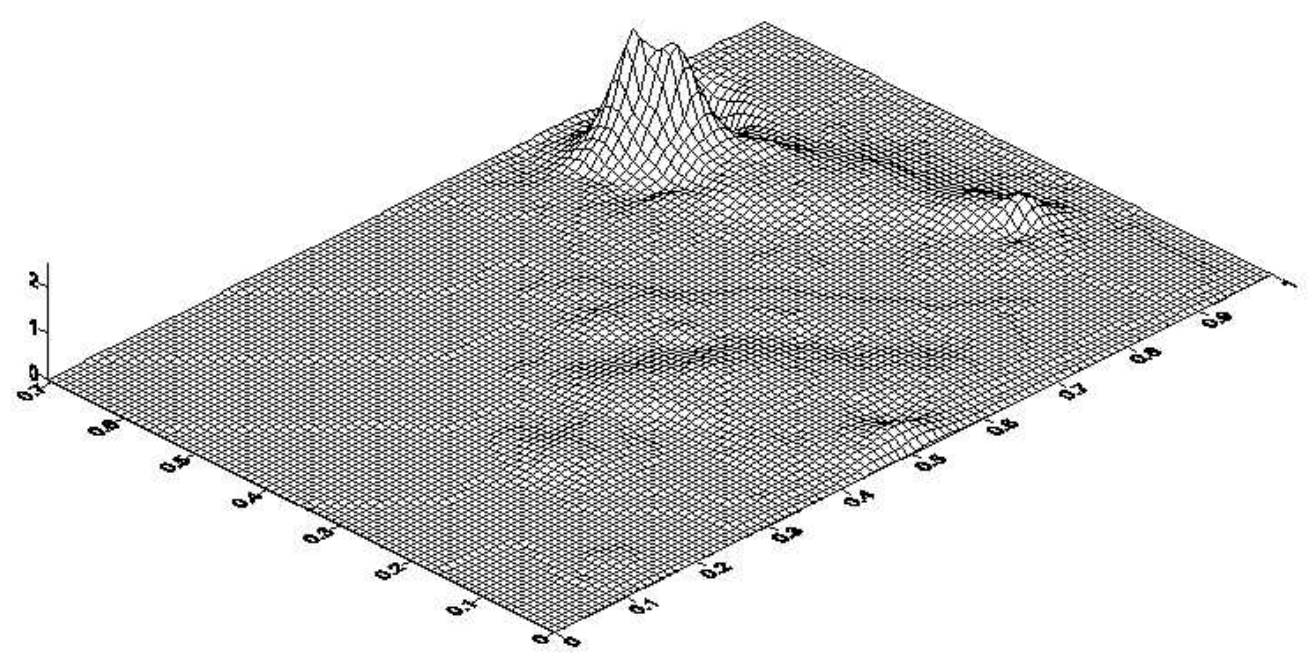

$260 \times 166 \mathrm{~mm}(72 \times 72 \mathrm{DPI})$ 


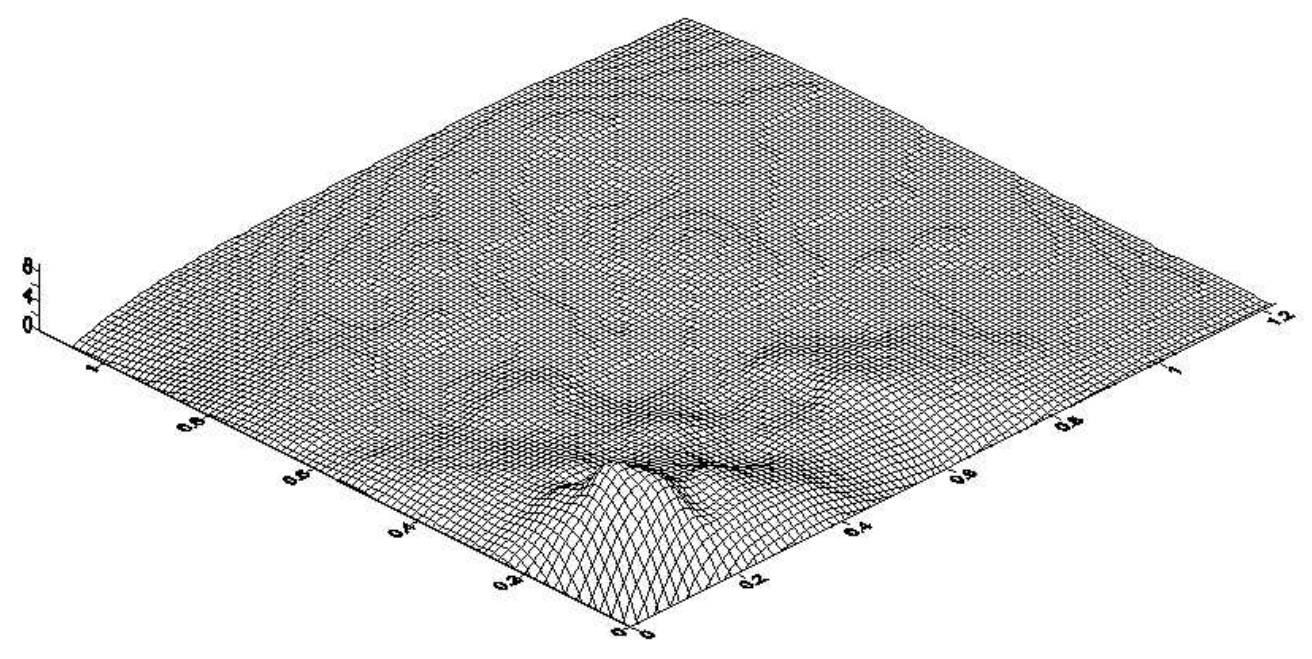

$289 \times 266 \mathrm{~mm}(72 \times 72 \mathrm{DPI})$ 


1
2
3
4
5
6
7
8
9
10
11
12
13
14
15
16
17
18
19
20
21
22
23
24
25
26
27
28
29
30
31
32
33
34
35
36
37
38
39
40
41
42
43
44
45
46
47
48
49
50
51
52
53
54
55
56
57
58
59
60

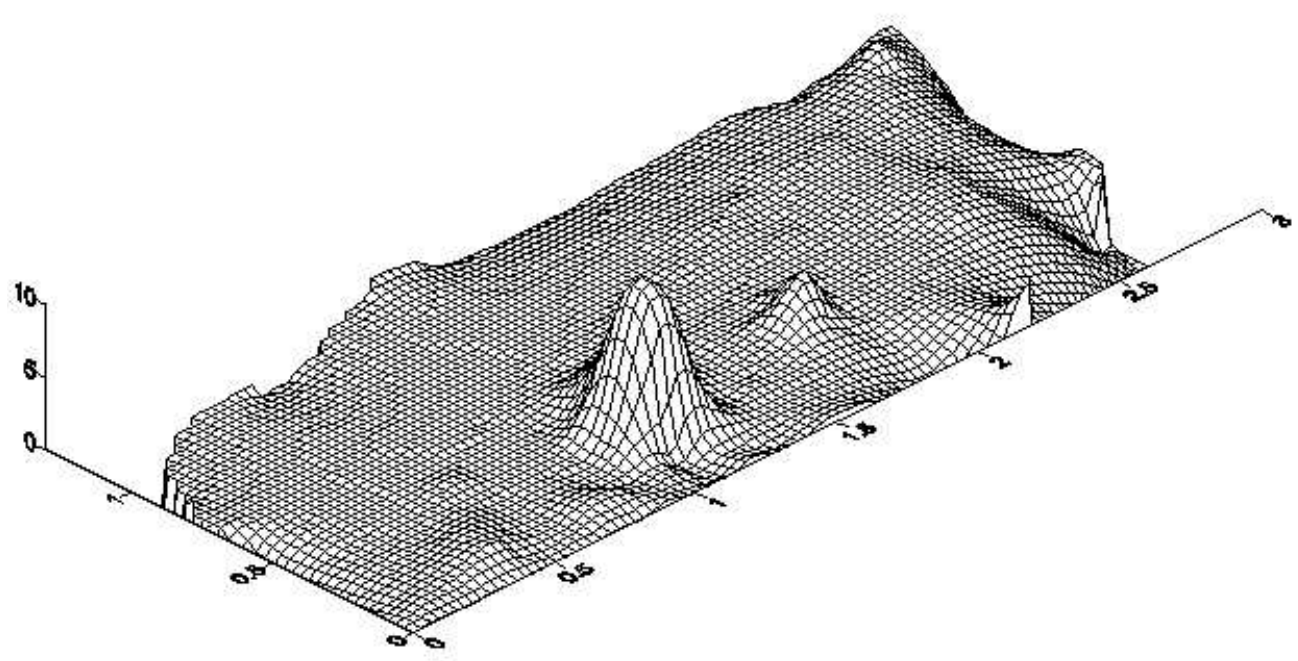

$220 \times 146 \mathrm{~mm}(72 \times 72$ DPI $)$ 


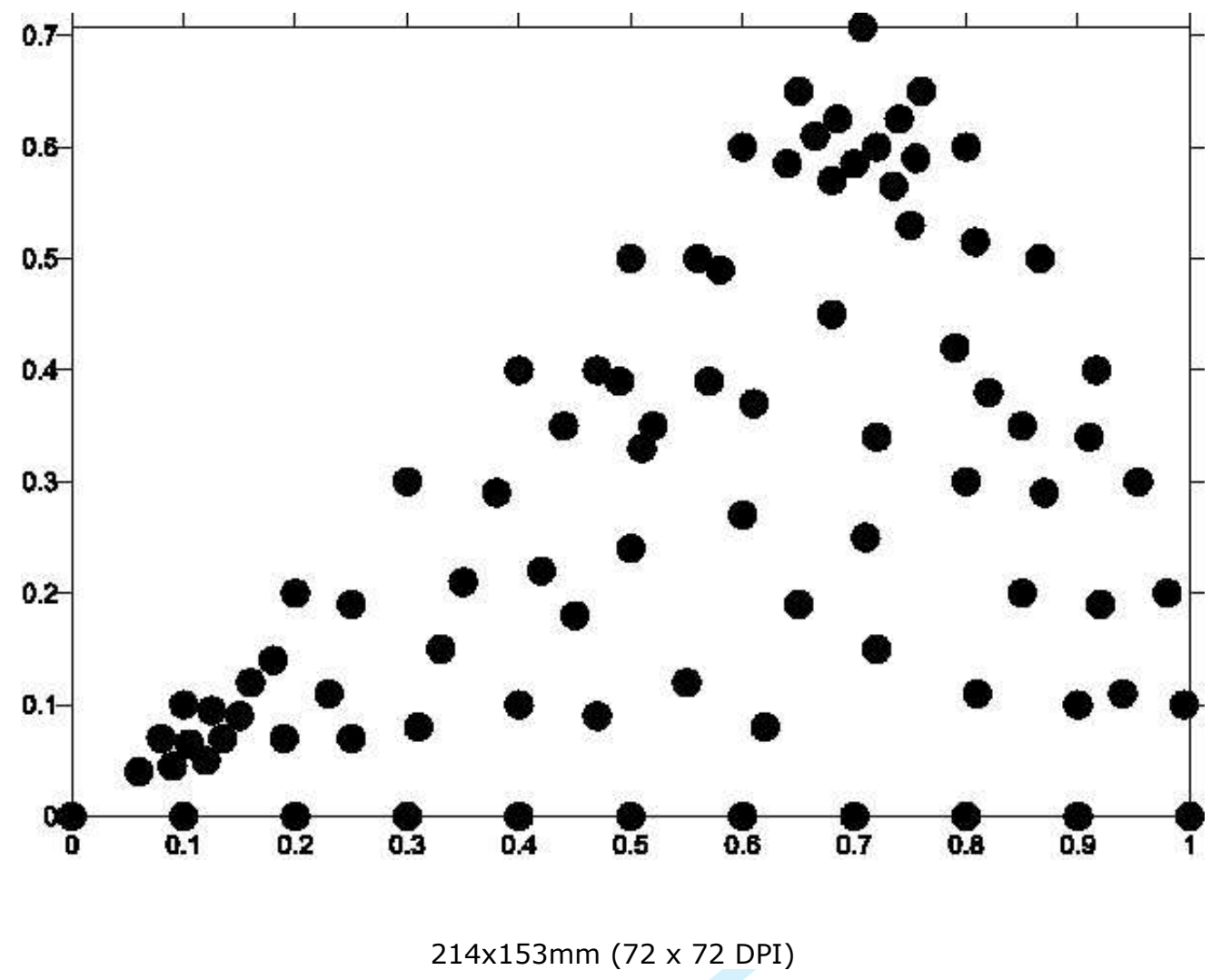

34

35

36

37

38

39

40

41

42

43

44

45

46

47

48

49

50

51

52

53

54

55

56

57

58

59

60

URL: http://mc.manuscriptcentral.com/gcom E-mail: ijcm@informa.com 


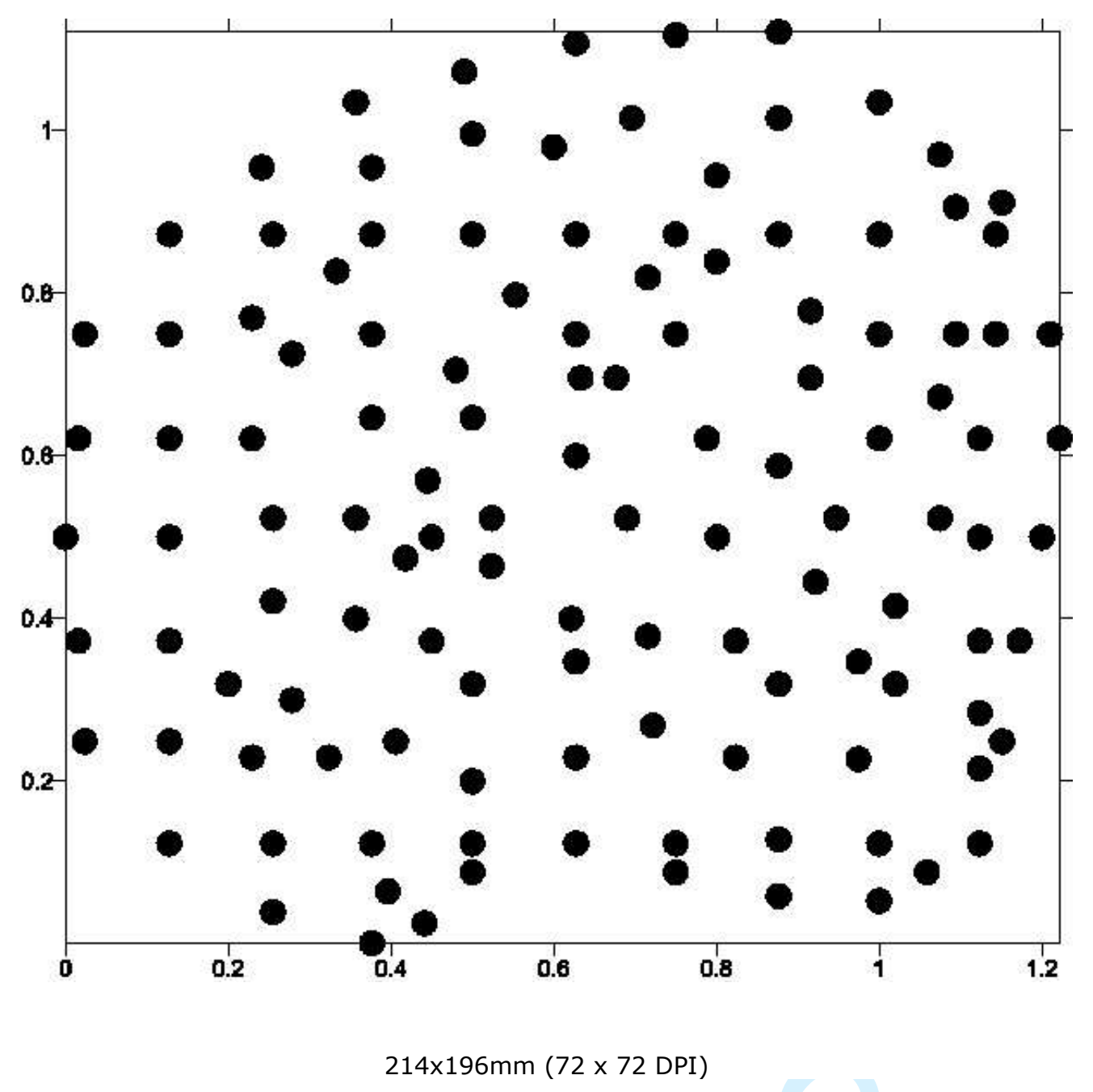

URL: http://mc.manuscriptcentral.com/gcom E-mail: ijcm@informa.com 


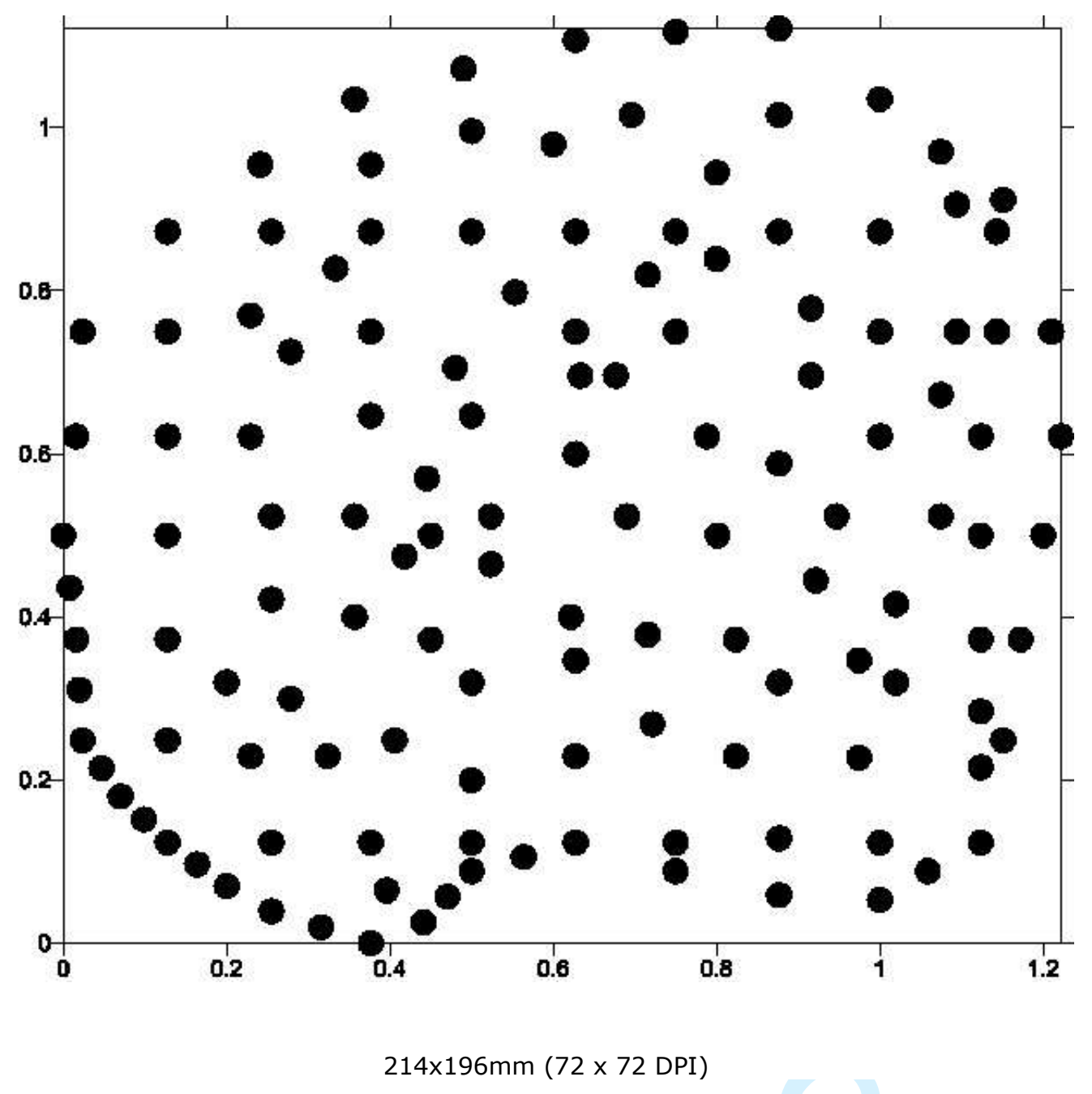

URL: http://mc.manuscriptcentral.com/gcom E-mail: ijcm@informa.com 


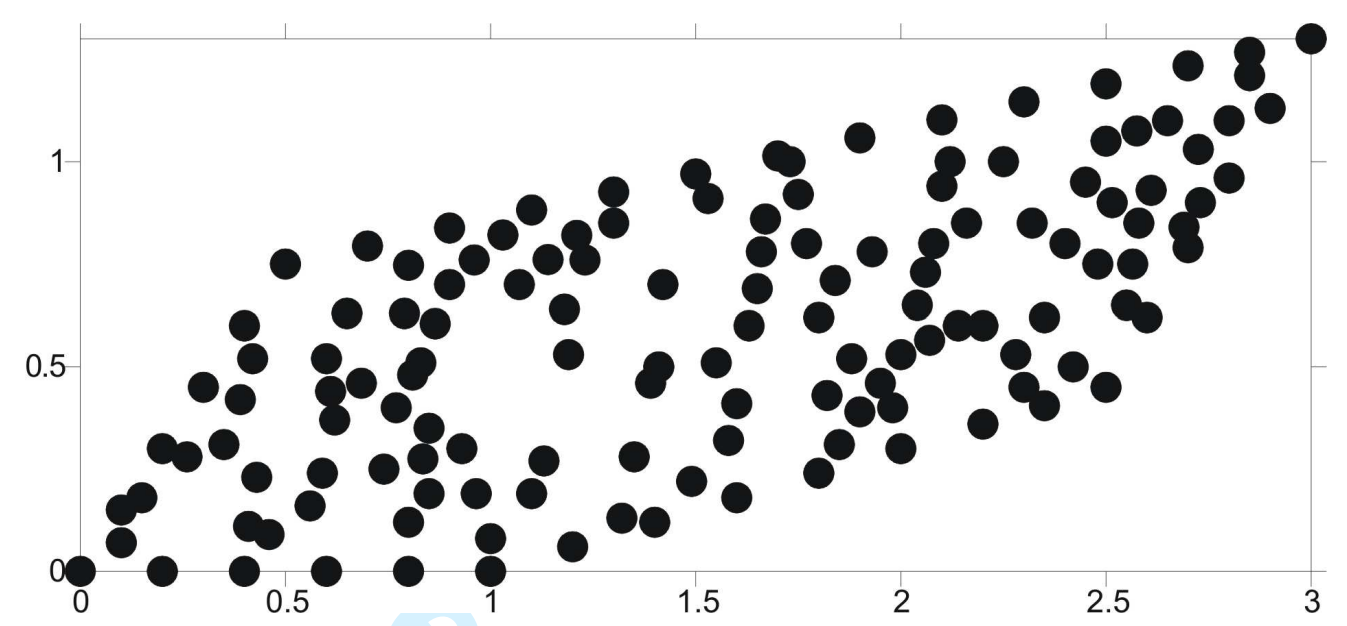




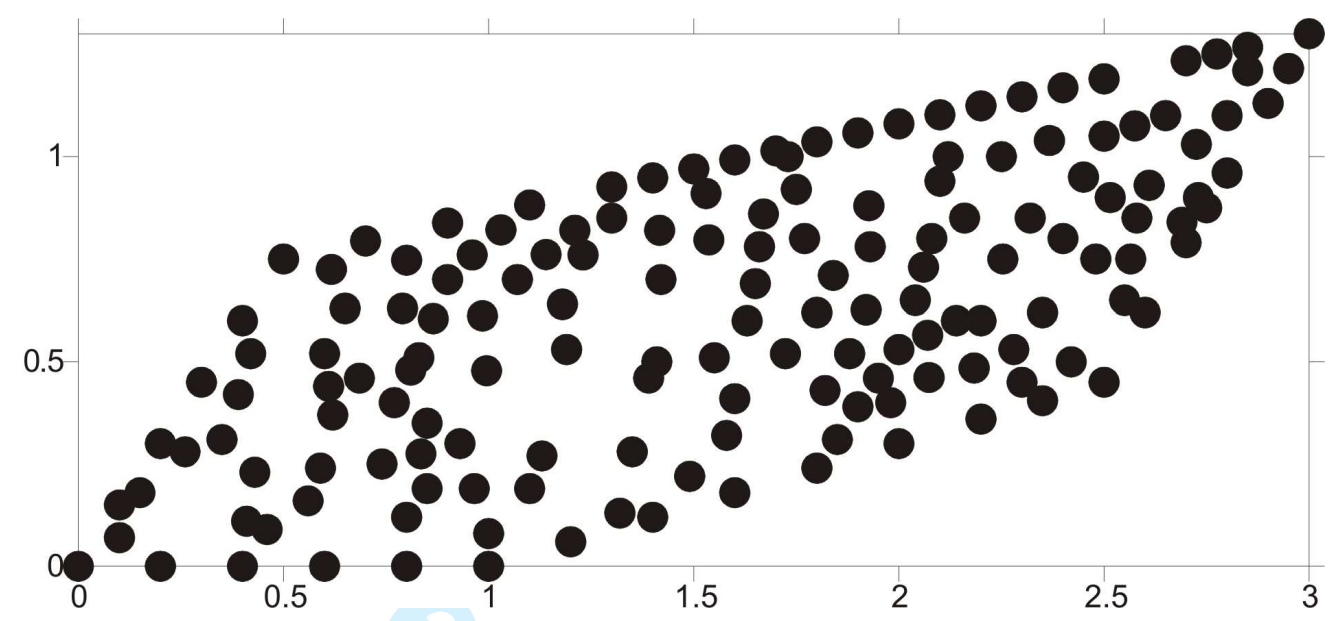




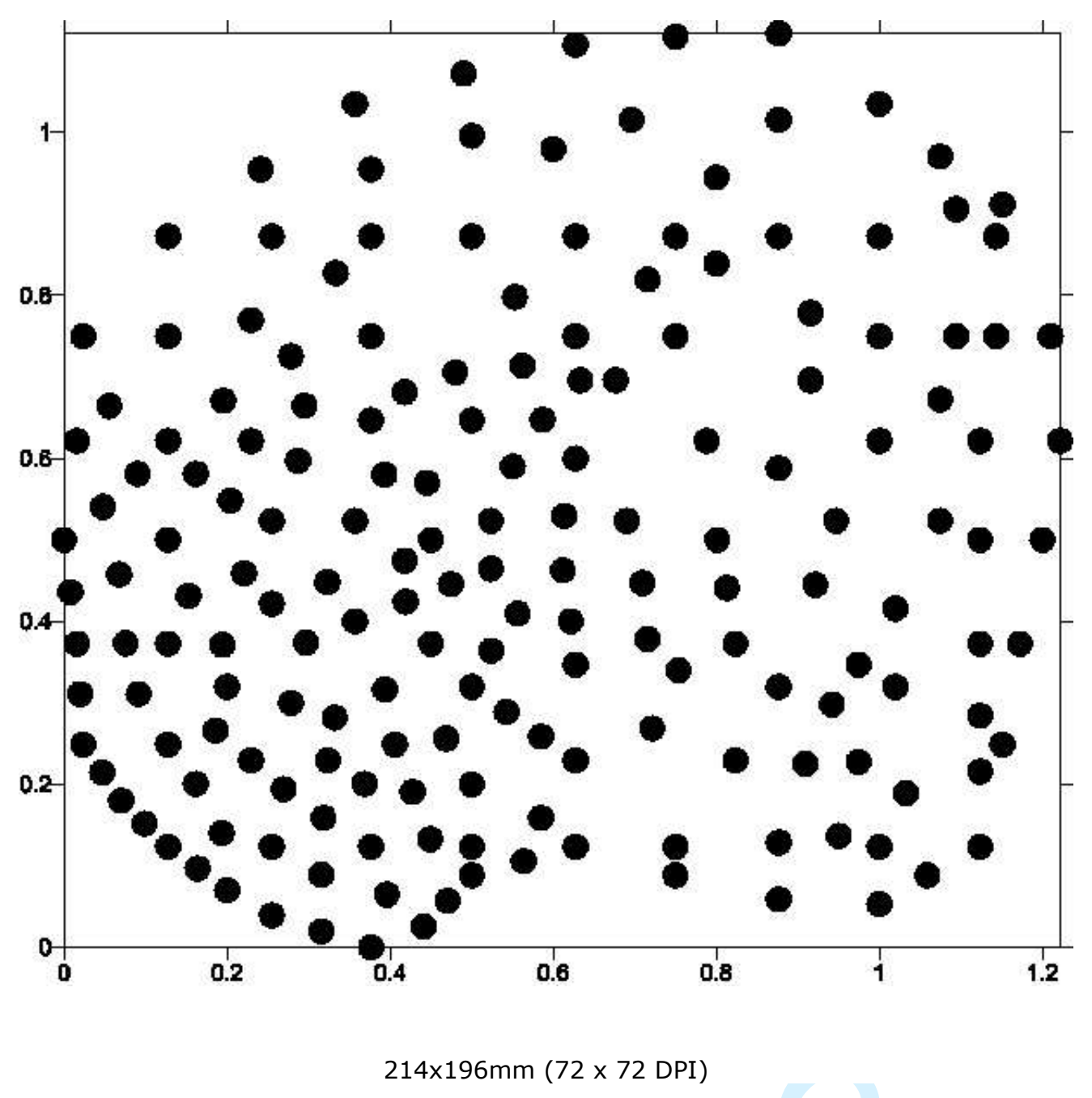

URL: http://mc.manuscriptcentral.com/gcom E-mail: ijcm@informa.com 


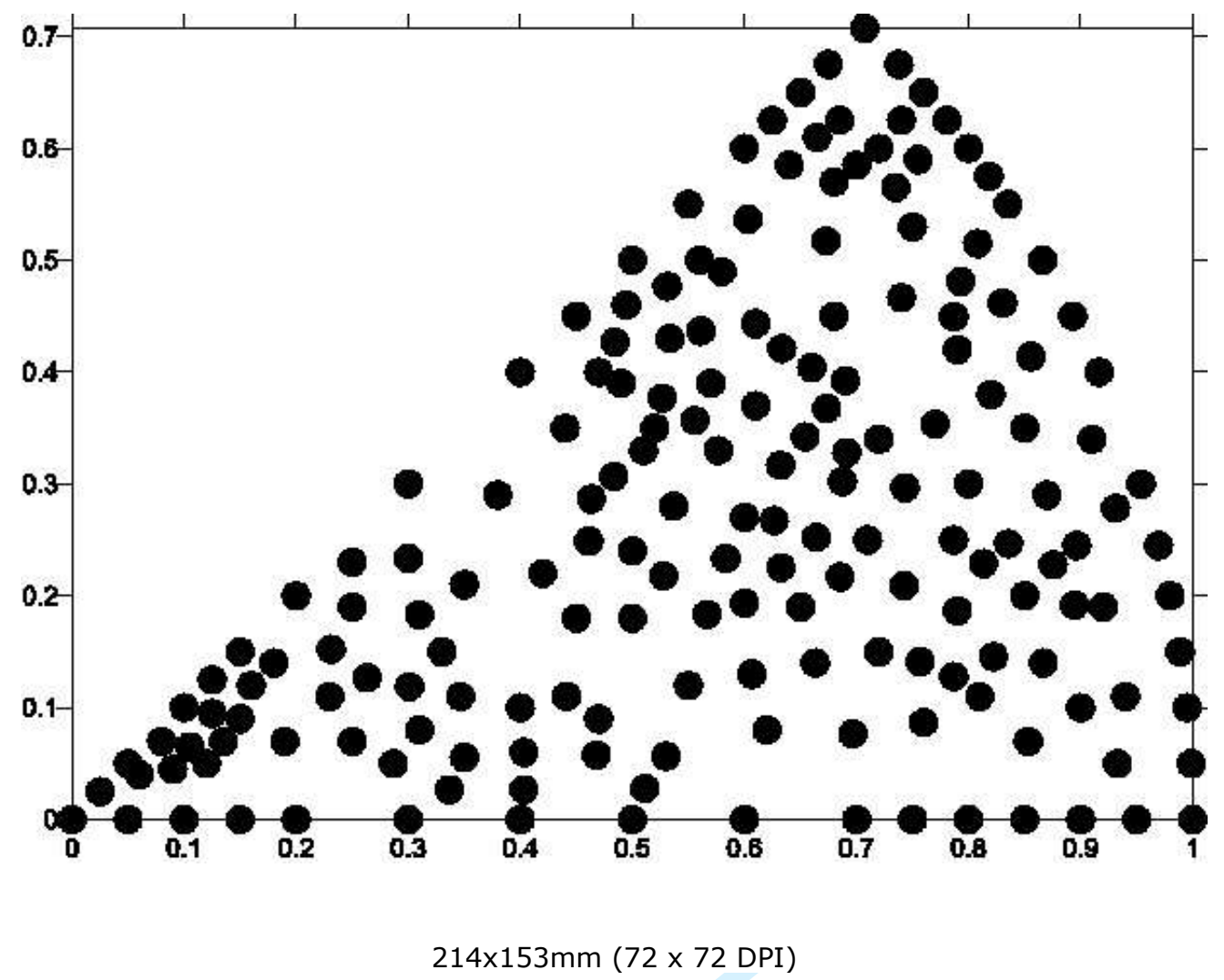

URL: http://mc.manuscriptcentral.com/gcom E-mail: ijcm@informa.com 